\title{
LAS FASES FORMATIVAS DE CHIAPA DE CORZO: NUEVA EVIDENCIA E INTERPRETACIONES
}

\author{
BRUCE R. BACHAND \\ New World Archaeological Foundation, Brigham Young University
}

\begin{abstract}
RESUMEN: Los recientes descubrimientos efectuados en Chiapa de Corzo están refinando nuestra comprensión del desarrollo cultural del sitio durante el periodo Formativo. El presente ensayo compara la evidencia nueva con las interpretaciones arqueológicas previas y con el trabajo actual en las regiones cercanas. Está germinando un entendimiento más detallado de Chiapa de Corzo, y con ello aparece una visión más clara del origen de una de las culturas mesoamericanas más antiguas, los zoques. La siguiente obra es más descriptiva que teórica. Trata los temas de cronología y, más que nada, las interpretaciones histórico-culturales que derivan de dicha cronología. Los asuntos que están aclarados o presentados por primera vez son: (1) los orígenes de la tradición de incensarios de la Depresión Central, (2) la naturaleza de la fase crítica llamada Chiapa II-B en Chiapa de Corzo, (3) nuevas ideas sobre las ofrendas extraordinarias de depósitos masivos de hachas que fueron contemporáneas con la Tumba 1 del Montículo 11, (4) algunas observaciones críticas sobre el origen y la irradiación de la cerámica tipo Nicapa Naranja-negativo, (5) contextos asociados con la fase recién identificada de Chiapa III-B, y (6) el fechamiento nuevo del cementerio que corresponde a la fase Chiapa IV o Francesa.
\end{abstract}

Palabras clave: periodo Formativo, Chiapas, zoque, olmeca, maya.

ABstRact: New discoveries at Chiapa de Corzo are refining our understanding of the site's Formative period development. This essay compares the latest evidence with past archaeological interpretations and ongoing work in neighboring regions. A more detailed understanding of Chiapa de Corzo is emerging, and with it comes a clearer view of the origin of one of Mesoamerica's more ancient cultures, the Zoque. The following contribution is more descriptive than theoretical. It gives priority to matters of chronology and the culture-historical entailments of that chronology. Clarified or presented for the first time are: (1) the beginnings of the Central Depression censer tradition, (2) the nature of the critical Chiapa II-B phase at Chiapa de Corzo, (3) new insights concerning the extraordinary axe deposits that were contemporaneous with Mound 11's Tomb 1, (4) critical observations on the origin and dispersal of Nicapa Orange-resist pottery, (5) contexts associated with a newly identified Chiapa III-B phase, and (6) the re-dating of the Chiapa IV Francesa phase cemetery.

Kerwords: Formative Period, Chiapas, Zoque, Olmec, Maya.

RECEPCIÓn: 9 de noviembre de 2012.

ACEPTACIÓN: 25 de febrero de 2013. 



\title{
LAS FASES FORMATIVAS DE CHIAPA DE CORZO: NUEVA EVIDENCIA E INTERPRETACIONES
}

\author{
BRUCE R. BACHAND \\ New World Archaeological Foundation, Brigham Young University
}

\section{Introducción}

Este ensayo es la conjunción de lo que deberían ser varios trabajos separados y más detallados acerca de la historia cerámica de Chiapa de Corzo y las diversas interpretaciones que se han propuesto en los últimos 60 años respecto a su composición étnica a lo largo del tiempo. He tratado de abordar estos temas en forma simultánea, aunque parcial, con el fin de discutir varios aspectos: (1) el desarrollo local y regional de los incensarios cerámicos, (2) la presencia temprana del Complejo de Conmemoración Astronómica, con sus depósitos masivos de hachas y sus elaborados recintos funerarios, (3) el origen y dispersión de la cerámica tipo Nicapa Naranja-negativo, y (4) las nuevas evidencias para la existencia de una faceta tardía (ca. 500-400 a.C.) de la fase Escalera o Chiapa III en el sitio. Tales temas serán abordados en orden cronológico comenzando con la ocupación más temprana del sitio para concluir con su última expresión original del periodo Formativo, correspondiente a la fase Francesa o Chiapa IV (figura 1). Hago referencia a otros sitios mesoamericanos para poner en contexto los hallazgos descritos (figura 2).

\section{El Proyecto Arqueológico Chiapa de Corzo}

El Proyecto Arqueológico Chiapa de Corzo se encuentra dirigido en forma conjunta por el autor de este texto y por el doctor Emiliano Gallaga-Murrieta, director del Centro INAH Chiapas. Es importante destacar también la participación del doctor John E. Clark, anterior director de la Fundación Arqueológica Nuevo Mundo, en el desarrollo de la estrategia inicial para los trabajos de campo a partir de 2008, junto con el sustancial apoyo del equipo, el personal y todas las facilidades necesarias para su ejecución. Los trabajos desarrollados durante las temporadas 2008 y 2010 contaron con la ayuda administrativa de Emiliano Gallaga, promotor de la investigación científica en Chiapas que realizó acciones encaminadas a la protección y adquisición de los terrenos aledaños al sitio, fuertemente amenazados por el avance urbano. Gracias a ello, muchas de las excavaciones 


\begin{tabular}{|c|c|c|c|c|}
\hline Chiapa & Periodo cultural & Fase local & $\begin{array}{c}\text { Etapa } \\
\text { arquitectónica }\end{array}$ & $\begin{array}{c}\text { Fechas estimadas } \\
\text { (no calibradas) }\end{array}$ \\
\hline VIII & $\begin{array}{l}\text { Clásico } \\
\text { Temprano }\end{array}$ & Jiquipilas & $\mathrm{J}$ & 350-450 d.C. \\
\hline VII & Protoclásico 3 & Istmo & I & 200-350 d.C. \\
\hline VI & Protoclásico 2 & Horcones & $\mathrm{H}$ & 0-200 d.C. \\
\hline V & Protoclásico 1 & Guanacaste & G & 150-0 a.C. \\
\hline IV & Formativo Tardío & Francesa & $\mathrm{F}$ & 400-150 a.C. \\
\hline III-B & \multirow{2}{*}{$\begin{array}{c}\text { Formativo } \\
\text { Medio (Tardío) }\end{array}$} & \multirow{2}{*}{$\begin{array}{c}\text { Etzpa } \\
\text { Escalera }\end{array}$} & \multirow{2}{*}{ E } & 550-400 a.C. \\
\hline III-A & & & & 750-550 a.C. \\
\hline II-B & \multirow{2}{*}{$\begin{array}{c}\text { Formativo } \\
\text { Medio (Temprano) }\end{array}$} & \multirow[t]{2}{*}{ Dzemba } & \multirow{2}{*}{ D } & 850-750 a.C. \\
\hline II-A & & & & 950-850 a.C. \\
\hline hiatus? & & & & 1000-950 a.C. \\
\hline $\mathrm{I}-\mathrm{B}$ & \multirow{2}{*}{$\begin{array}{l}\text { Formativo } \\
\text { Temprano }\end{array}$} & \multirow{2}{*}{ Cotorra } & \multirow{2}{*}{$\mathrm{C}$} & 1050-1000 a.C. \\
\hline $\mathrm{I}-\mathrm{A}$ & & & & 1150-1050 a.C. \\
\hline
\end{tabular}

Figura 1. Cronología de Chiapa de Corzo.

descritas en este trabajo se encuentran, o se encontrarán pronto, bajo la protección del Instituto Nacional de Antropología e Historia. El financiamiento principal para este proyecto fue proporcionado por la Fundación Arqueológica Nuevo Mundo de la Universidad Brigham Young, la National Geographic Society, una Beca Fulbright-García Robles otorgada al autor, y numerosos donadores privados en los Estados Unidos. El trabajo de campo y el estudio de los artefactos han sido llevados a cabo por Bruce R. Buchand en colaboración con la maestra Lynneth S. Lowe, actual Coordinadora del Centro de Estudios Mayas del Instituto de Investigaciones Filológicas de la Universidad Nacional Autónoma de México. Así, este proyecto representa un esfuerzo de colaboración binacional con varias instituciones que incluye a diversos especialistas de México y los Estados Unidos. 


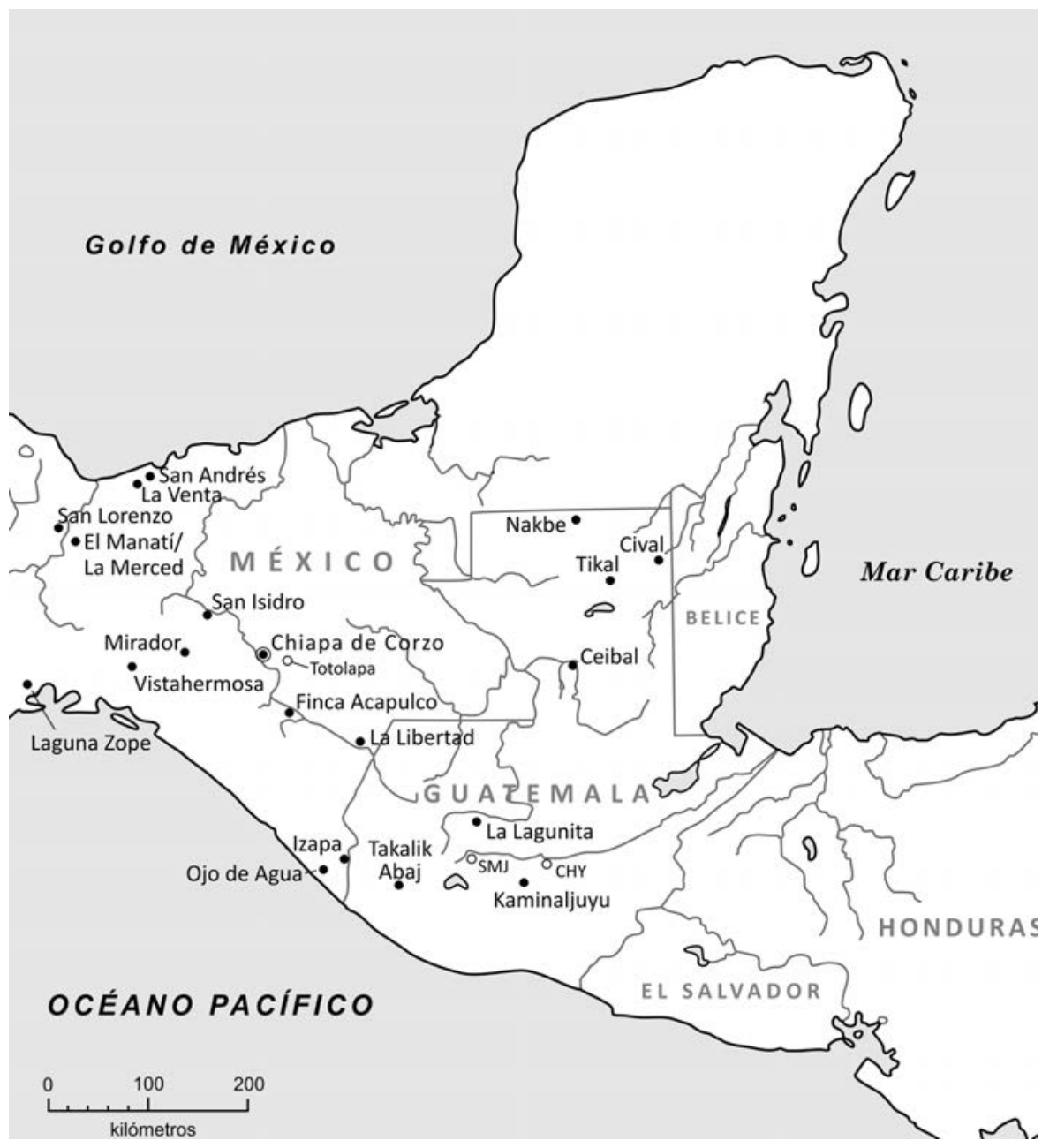

Figura 2. Mapa de Mesoamérica indicando los sitios mencionados en el texto.

El objetivo del proyecto consiste en esclarecer la identidad o identidades culturales de la antigua población de Chiapa de Corzo, al tiempo que nos permitirá refinar la cronología del sitio a partir de análisis estratigráficos, estudios cerámicos y fechamiento Bayesiano de radiocarbono. Estos trabajos se encuentran aún en sus primeras etapas, pero los avances realizados hasta el momento han aportado datos novedosos e interpretaciones originales que enriquecerán nuestra comprensión de esta antigua capital mesoamericana.

Durante la temporada 2008 se llevó a cabo la reexcavación de dos grandes trincheras practicadas originalmente por la Fundación Arqueológica Nuevo Mundo en el Cuadrante Suroeste, aún sin publicar en su totalidad, lo cual repre- 
sentó una invaluable oportunidad para aclarar la secuencia de desarrollo del núcleo ceremonial del sitio, obteniendo así muestras controladas de suelos, obsidiana, restos botánicos y muchas otras clases de artefactos que durante los años cincuenta y sesenta no fueron recolectados en forma sistemática (figura 3). Posteriormente, nuestras excavaciones del Montículo 11 realizadas durante la temporada de 2010 representan la primera exploración intensiva de un edificio público de importancia realizada desde 1971 en Chiapa de Corzo. Muchos de los argumentos que aquí presentaré no tendrían un mérito científico de no haber sido por tales excavaciones.

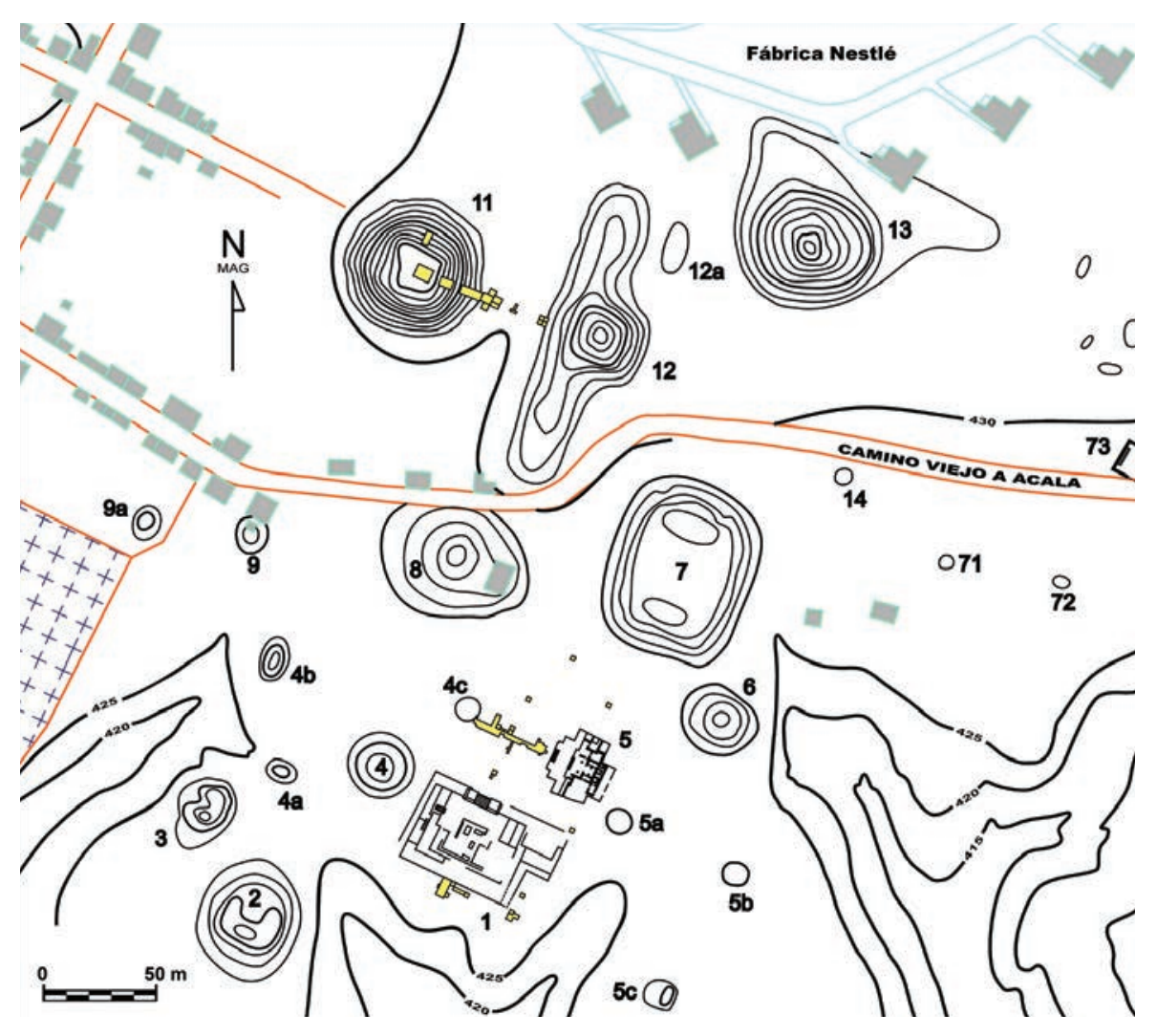

Figura 3. Plano de la parte sur del centro ceremonial de Chiapa de Corzo que muestra las excavaciones de 2008 y 2010.

\section{Evidencias del periodo Formativo Temprano}

Algunos años antes de nuestras excavaciones, John Clark y David Cheetham (2005) propusieron una nueva subdivisión cronológica para la primera ocupación cerá- 
mica de Chiapa de Corzo, la fase Cotorra o Chiapa I. Una nueva fase cerámica, denominada Jobo, fue deducida a partir del estudio comparativo de las colecciones tipológicas resguardadas en las instalaciones de la Fundación Nuevo Mundo, en San Cristóbal de las Casas (Cheetham y Lee, 2005). El término "Jobo" fue utilizado para asociar los eventos de Chiapa de Corzo con la fase Jocotal de la Costa Pacífica, una fase puente entre Cotorra y Dili. Sin embargo, a diferencia de las otras fases de Chiapa de Corzo previamente establecidas, Jobo presenta ciertos problemas. En principio incluye muchos de los mismos tipos y modos cerámicos encontrados en Cotorra, sólo que con diferentes frecuencias (Clark y Cheetham, 2005: 337). Pero quizás lo más discutible radica en que la fase Jobo no tiene un sustento estratigráfico; sus tiestos diagnósticos fueron escogidos de escombros secundarios o redepositados de la fase Cotorra, es decir, de contextos mezclados o revueltos (Dixon, 1959: 1). De hecho, a pesar de las afirmaciones iniciales de Bruce Warren (1961: 76), no se han encontrado basureros, fogones, construcciones o superficies de ocupación correspondientes a la fase Cotorra en Chiapa de Corzo (Lowe y Agrinier, 1960: 7). Nuestras excavaciones profundas y extensivas de 2008 y 2010 no lograron detectar depósitos múltiples o superpuestos de Chiapa I. Debido a ello, no existe hasta el momento evidencia estratigráfica sólida para esta fase cerámica recién propuesta.

Las investigaciones desarrolladas por Timothy Sullivan (2009), de la Universidad de Pittsburgh, identificaron cuatro sitios fechados únicamente para Chiapa I en el hinterland de Chiapa de Corzo. Él recolectó 13 tiestos diagnósticos de superficie en dichos lugares (Sullivan, 2009: Apéndice E). Utilizando los criterios de Clark y Cheetham para la fase Jobo, Sullivan describió tales tiestos como "Jobo". No resulta una sorpresa que no reconociese ningún sitio sólo con cerámica Cotorra.

¿Qué es, entonces, lo que debemos pensar de la fase Jobo? Con base en la ausencia de evidencias de una fase Cotorra estratigráficamente dividida, uno se ve llevado a inferir que Jobo es un sinónimo de Cotorra. Tal como Gareth Lowe (2007: 95) lo explicó antes de su fallecimiento: "la fase Cotorra o Chiapa I de Chiapa de Corzo se considera en la actualidad más equivalente a la fase Jocotal de la Costa Pacífica (fase Jocote del Alto Grijalva) y no a la fase Cuadros/Olmeca Temprano, explicando así la diferencia tipológica en su contenido cuando se compara con la fase Pac de Mirador" (Lowe, 1991: 114). Elementos tales como los tipos Calzadas Grabado y Limón Inciso, la cerámica negra de borde blanco y los tecomates con bordes convexos (usualmente con engobe rojo) resultan muy poco frecuentes en Chiapa de Corzo como para ubicar Cotorra en la primera mitad de la fase San Lorenzo (Lowe, 2007: 90).

Hasta que no se logren identificar las fases Cotorra y Jobo en depósitos sin mezclar en Chiapa de Corzo, considero que debe mantenerse el uso del nombre de Cotorra para designar la primera fase cerámica del sitio. Tal como lo sugirió Lowe, Cotorra es simplemente un complejo correspondiente a Jocotal con presencia mínima de algunos tipos Cuadros más tempranos. Al introducir 
otra denominación para tal complejo, "Jobo", se está implicando la existencia de dos ocupaciones de Chiapa I subsecuentes y culturalmente distintivas, algo que no resulta sustentable arqueológicamente. ¿Por qué inquietarse con este asunto terminológico aparentemente inocente? En principio, la utilización del término "Cotorra" evita confusiones innecesarias en el momento de sintetizar antiguos y nuevos datos de excavación. Pero, aún más importante, al mantener el término original reconocemos un escenario histórico viable: que Chiapa de Corzo tuvo una ocupación del Formativo Temprano que difería en su contenido y naturaleza de los complejos aledaños. Varias diferencias regionales así como temporales resultan evidentes entre los complejos Chiapa I de Chiapa de Corzo, San Isidro y Mirador (Agrinier, 2000; Lowe, 1998: 38-43). Es muy posible que cantidades menores de cerámica de la fase San Lorenzo Temprana fuesen apreciadas como reliquias, comerciadas o copiadas por los primeros habitantes de Chiapa de Corzo. Esta perspectiva solamente podrá ser esclarecida a partir de la excavación de contextos primarios del Formativo Temprano en Chiapa y sus asentamientos vecinos. Aunque la diferenciación local puede ser una opción, yo favorezco la idea de mantener a Cotorra como la única fase de ocupación del Formativo Temprano. Hemos examinado, hasta la fecha, varios miles de tiestos de Chiapa procedentes de las excavaciones recientes. Si nuestras observaciones de campo, las descripciones tipológicas de Clark y Cheetham y los datos del recorrido de Sullivan resultan ser indicativos de los resultados futuros, entonces una subdivisión de Cotorra como Cotorra A y B sería una mejor solución taxonómica que la aplicación de una nueva designación de fase. Esto haría a Cotorra más o menos comparable con Cacahuanó A y B de San Isidro. Tal división prevendría que la segunda mitad de Chiapa I fuese tratada como un complejo cerámico distinto, lo cual no parece probable. La designación Cotorra B también permitiría que el sistema alfabético del sitio pudiese ser aplicado sin confusión a futuras construcciones del Formativo Temprano. De esta forma, se logra el refinamiento histórico, se respeta la distinción local de la secuencia cerámica y se mantiene la coherencia del sistema de registro.

Lowe, Clark y Cheetham han demostrado la contemporaneidad de la segunda parte de Cotorra y Jocotal. Esta observación recorta 350 años del inicio de la fase, moviendo la ocupación inicial de Chiapa de Corzo de 1500 a 1150 a.C. Sin embargo, los problemas con Cotorra no se limitan a las sutilezas de la cerámica. Hallazgos estratigráficos demuestran de forma consistente que un hiato ocupacional ocurrió entre Cotorra y la fase Dili Chiapa II, un abandono que duró probablemente varios años o unas cuantas décadas. A diferencia de las creaciones de los períodos posteriores, las de los cotorreños no se incorporan en construcciones posteriores ni en la planificación del sitio. Fueron arrasadas y borradas, un patrón replicado en otros lugares del oeste de Chiapas (Agrinier, 2000: 167-168; Lowe, 2007: 98-99 y s.f.: 30). Por lo tanto, los orígenes y la identidad cultural de los sucesivos ocupantes de la fase Dili sigue siendo un tema de investigación de alta prioridad. La población de Dili fue considerablemente mayor que la de Cotorra, 
tal vez llegando a cien mil habitantes a través de los sectores central y occidental de la Depresión Central. Las estimaciones de la población Dili en Chiapa de Corzo de 1691 (Sullivan, 2009: figura 1681) y 2511 habitantes (Warren, 1978: figura B-1) parecen bajas para las cantidades de cerámica recientemente encontradas en el sitio. El conjunto material de los residentes Dili —específicamente su vajilla gris/blanca con desgrasante de hornablenda y motivos monótonos de doble línea quebrada, braseros con cuernos, y la continuación de una predilección inexplicable por los tecomates - se diferencia de las tradiciones culturales contemporáneas del Golfo, de las costas del Pacífico y de la región maya. Por otra parte, las mercancías importadas, como cerámica, concha, obsidiana y jade, son muy raras o inexistentes en la parte inicial de Dili. En resumen, la nueva evidencia forma un escenario histórico desconcertante: el establecimiento de una sociedad bastante grande, aislada y homogénea en la mitad occidental de la Depresión Central con ambiguos, si no es que incongruentes, lazos ancestrales con los residentes previos de la fase Cotorra.

\section{Los comienzos del Formativo Medio}

Los recientes hallazgos de Chiapa de Corzo proporcionan una evidencia sólida de que el centro monumental, con sus templos piramidales y sus estanques públicos, fue creado en la época Chiapa II-B, entre 850 y 750 a.C. (fechas no calibradas). Al menos dos de los tres elementos que conforman el plan de los sitios del Formativo Medio en Chiapas (Clark, 2000: 47; Clark y Hansen, 2001: 4), el Grupo tipo E y la pirámide al norte, estaban ya presentes en la fase Dzemba II-B. Los alargamientos laterales que conectaban con el lado sur del Montículo 17 fueron construidos también en este momento (Lowe, 1962: 56). No resulta posible saber si tales rasgos fueron anteriores, contemporáneos o posteriores a aquellos ubicados en el Complejo A de La Venta, ya que en estos últimos no se pudo encontrar estratigrafía o artefactos fechables (Drucker et al., 1959: 111). Los Montículos 7 y 17 aparentemente no tenían construcciones Chiapa II (Lee, 1969: 22; Lowe, 1962: 45), y el Montículo 13 no ha sido probado suficientemente para determinar esto (Hicks y Rozaire, 1960: 5). Así, por lo menos, se puede decir que el Grupo E (Montículos 11 y 12), la pirámide norte (Montículo 36) y los montículos paralelos de Montículo 17 fueron los precursores del plan MFC (Middle Formative Chiapas) en Chiapa de Corzo. Un dato importante que resulta de la observación anterior es que las ofrendas y las instalaciones funerarias de estilo olmeca aparecieron después del levantamiento de dichas construcciones monumentales (Bachand y Lowe, 2011).

Todas las construcciones Dili muestran una orientación de 20 a 23 grados al este del norte. En ese sentido, es importante notar que la orientación de Ojo de Agua, el sitio más grande de la Costa Pacífica durante la fase Jocotal (ca. 1000900 a.C.), también es de 20 grados al este (Clark y Hodgson, 2007-2008: figura 
5; Pinkowski, 2006: 49), mientras que la orientación de La Venta, Laguna de los Cerros y San Isidro es de 8 grados al poniente. Es significativo notar dicha realidad porque ello nos motiva a reconsiderar las relaciones históricas que pudieron haber existido entre estas regiones culturales en los albores del periodo Formativo Medio. Por ejemplo, si el plan MFC se originó en La Venta como piensa Clark (2000; Clark y Hansen, 2001), la evidencia claramente indicaría que los pobladores de la Depresión Central reorientaron el plano para ajustarlo o conformarlo a ideas simbólicas regionales. Pero tal vez la dirección de las influencias no fue así. La orientación de Ojo de Agua sugiere que la inspiración para el plano MFC se originó entre las poblaciones Jocotal de la región Soconusco de Chiapas, una cultura que sospechamos inmigró a la Depresión Central antes del Formativo Medio (Clark et al., 2005; Lowe, 2007). Es posible que sitios como Finca Acapulco y Chiapa de Corzo derivasen su planificación temprana a partir de sus contactos con la Costa Pacífica y no necesariamente con La Venta.

Debe hacerse una mención especial con respecto a los "estanques públicos" de agua. En esta época no tenemos evidencias definitivas de la construcción real de estanques o espejos de agua, elementos comunes en otros sitios olmecas (Stark, 1999). Esto se debe a que aún debemos confirmar la presencia de orillas formalmente construidas para el antiguo pantano o cuerpo de agua que originalmente cubría gran parte del Cuadrante Suroeste del sitio en épocas Cotorra, Dili y Escalera (Bachand et al., 2008: 59, 77; Lowe, 1962: 36). Los alineamientos de piedra de la fase Dili hallados durante la temporada 2008 representan posibles candidatos para tales elementos (Bachand et al., 2008: 48, 70, figuras 31 y 44). El largo drenaje de piedra descubierto sobre la roca madre en la parte trasera del Montículo 5 podría estar relacionado con las modificaciones de la fase Dili de este cuerpo de agua (Lowe, 1962: 42, láminas 30g y 30h). Ahora contamos con excelentes evidencias de que el poblado de la fase Dili fue construido directamente encima del pantano (Lee, 1969: 22), el cual fue rellenado en algunas secciones (Bachand et al., 2008: 48) y drenado en otras, con el fin de obtener grandes cantidades de un barro negro y extremadamente denso que fue utilizado para la construcción de los Montículos 11, 12 y 32. Curiosamente, los rellenos más tempranos que encontramos en el corazón de Montículo 11 fueron arcillas negras pegajosas que emitieron un olor o aroma de petróleo.

Alguna continuidad cultural con la fase Cotorra precedente está indicada por el uso continuado de tecomates y la creciente popularidad en los incensarios (ver abajo). No obstante, las formas, diseños, acabado de superficie y composición de pasta de las vasijas de servicio cambian en forma notable. Dichas vasijas adquieren un gusto local, al igual que en la mayoría de las aldeas de esta época, mostrando ciertos símbolos panmesoamericanos, como el motivo de doble línea quebrada. La cerámica con engobe blanco es menos común que en las regiones aledañas; compone aproximadamente $30 \%$ del complejo Dili. Me parece que esta falta de congruencia entre las cerámicas con engobe de Cotorra y Dili podría deberse a un breve hiato ocupacional entre ambas fases. La razón principal de 
que los depósitos primarios de Cotorra hayan sido tan difíciles de ubicar radica en las labores de nivelación del área realizadas por los habitantes de la fase Dili, que eliminaron cualquier vestigio que se encontrase allí originalmente (Lowe y Agrinier, 1960: 7). Este comportamiento resulta contrapuesto con las subsecuentes ocupaciones del sitio, en las cuales se preservaron siempre las antiguas construcciones, incorporándolas dentro de las más recientes.

La diferenciación regional de la cerámica Dili de Chiapa de Corzo es algo que apenas comienza a ser apreciado en su magnitud. Los tipos Dili de este sitio forman un conjunto tipológico cerrado con complejos equivalentes a lo largo de la mitad occidental de la Depresión Central. Los dos tipos principales Dili con engobe, Vergel Blanco-a-Bayo y Vista Gris, representan versiones de la misma vajilla local, cuya principal característica consiste en una pasta de color gris a beige rosáceo con abundantes inclusiones de fenocristales de hornablenda. No se han identificado hasta el momento piezas de comercio procedentes de la costa del Golfo al interior de los gruesos depósitos de la fase Dili en Chiapa de Corzo. De hecho, existe muy poca evidencia del contacto directo entre tales centros durante esta fase. La Venta parece haber recibido una porción de su obsidiana de El Chayal a través del occidente de Chiapas, pero no es claro si esto pasó antes de Chiapa III. A diferencia de otras propuestas previas (Adams, 1971; Andrews, 1990), consideramos que la cerámica Dili presenta muy pocas correspondencias con la cerámica Xe de las Tierras Bajas mayas del sur (observaciones personales; véase también Clark et al., 2005: 103). Efectivamente, el motivo de doble línea quebrada que resulta tan monótono en Dili es mucho menos común al interior de los extraordinarios niveles Xe recientemente excavados en Ceibal (Takeshi Inomata, comunicación personal, 2010). Aún más curioso es el hecho de que la doble línea quebrada aparece raramente en cerámica de pasta similar en la Costa Pacífica del oriente de Oaxaca (observaciones personales). La cerámica oaxaqueña presenta paredes muy delgadas —en promedio casi la mitad del grosor de los ejemplares Dili. Los cajetes de fondo plano se encuentran presentes, pero los tecomates elaborados en pasta gris a beige parecen ser igualmente comunes. Es frecuente también ver una banda estriada de 3 a $4 \mathrm{~cm}$ por debajo del borde de los tecomates, algo bastante raro en Chiapa de Corzo. Tales diferencias podrían señalar la permanencia de una cultura mixe en la Costa Pacífica a lo largo del Istmo de Tehuantepec durante la época Chiapa II (Reyes y Winter, 2010; Vásquez y Winter, 2009). De ser así, la fase Dili parecería marcar el distanciamiento étnico inicial de los zoques de la Depresión Central de sus parientes mixes en las Costas Pacífica y del Golfo. La ausencia o escasez de cerámica Nicapa Naranja-negativa y de incensarios con picos en las fases subsiguientes sustenta la hipótesis de Winter de una separación mixe-zoque en los inicios del periodo Formativo Medio. John Clark y David Cheetham (2005: 290) llegaron a una conclusión similar en su detallado estudio comparativo de los complejos cerámicos chiapanecos. Desde esta perspectiva, parecería que las recientes reconstrucciones glotocronológicas propuestas para esta división resultan ser demasiado tardías por 4 o 5 siglos (Wichmann et al., 2008). 


\section{Los incensarios zoques}

En los inicios de la fase Chiapa II (ca. 900 a.C.) aparece una tradición de incensarios completamente desarrollada en las partes central y occidente de la Depresión Central de Chiapas. Esta tradición tiene antecedentes locales en la fase previa del Formativo Temprano, Chiapa I (Agrinier, 1984: figura 31; Lowe, s.f.: 65 y 1998: 55). Como se menciona arriba, la fase Chiapa I manifiesta conexiones directas con las culturas mixe-zoqueana y olmeca de las costas tropicales del Pacífico y Golfo. En su tesis de doctorado, David Cheetham (2010) ha identificado cuatro formas de brasero anular que compartieron Canto Corralito y San Lorenzo durante las fases Cherla (1250-1150 a.C.) y Cuadros (1150-1000 a.C.). ${ }^{1}$ Richard Lesure reportó (1998) antecedentes de dichos braseros en la misma planicie costal de los rellenos preolmecas del sitio Paso de la Amada. Aparecieron estos ejemplos tempranos alrededor de 1400 a.C. en la fase Locona (agradezco a John Clark llamar mi atención a esta información). Por lo tanto, no cabe duda de que los ejemplos de Paso de la Amada representan la tradición mesoamericana de incensarios más temprana registrada hasta la fecha. Esto implica que los incensarios fueron una innovación mixe-zoqueana de la cultura mokaya. Sin embargo, su uso y distribución más amplia se encuentran en la Depresión Central de Chiapas entre los descendientes inmediatos de los mokayas, los zoques (figura 4).

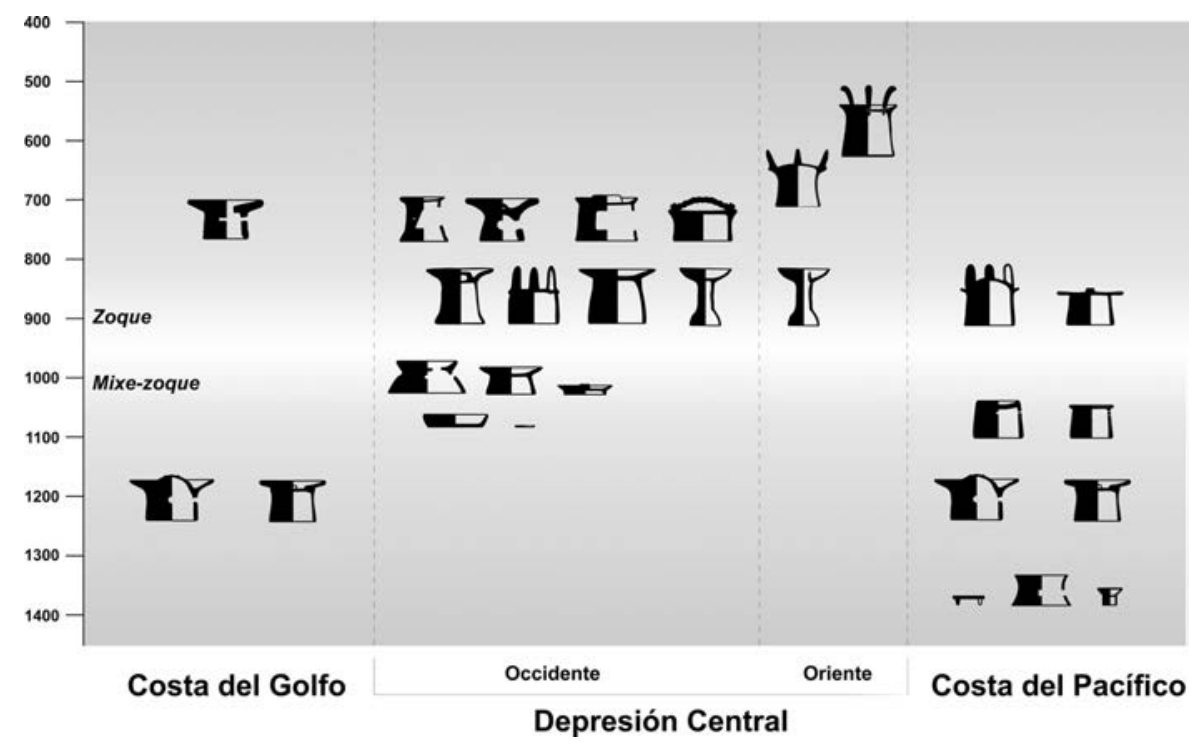

FiguRA 4. Cuadro cronológico de las formas de incensarios de la Depresión Central.

${ }^{1}$ N. B. Las fechas que aplica Cheetham a la fase Cuadros se traslapan con las fechas aceptadas para la parte inferior de la fase Jocotal, equivalente a Chiapa I-B. 
La primera manifestación de tal tradición, el brasero anular, se encuentra primero entre los mokayas del Mazatán y después extensamente distribuido desde la región Mazatán hasta la zona nuclear olmeca del Golfo y allende (Cheetham, 2010: 231-232, 262, 422-423, figuras 2b, 4i, 5o, 6.2, 6.7, 6.9, 14c, 16d; Coe y Diehl, 1980: 152, 285, figuras 120n y 402; Grove, 1989: 142). Algunos comales e incensarios de cajete con fondo plano y paredes ligeramente evertidas también han sido fechados para el Formativo Temprano (Lowe, s.f.), pero estos probablemente se fechan en la fase Chiapa I-B (equivalente a Jocotal). Fragmentos de incensarios emergieron con frecuencia en los rellenos constructivos de Chiapa Il e inicios de Chiapa III al interior del Montículo 11. Fueron un aspecto común e integral a la cultura zoque que floreció a partir del Formativo Medio en la Depresión Central.

Los investigadores consideran que los braseros pudieron haber contenido el carbón para calentar o ahumar ciertos alimentos (Miller et al., 2005: 166; Grove, 1989: 142; Lowe, s.f.). Otros incensarios pueden haber sido utilizados a manera de lámparas portátiles en las casas (Lowe, s.f.). Pero su descubrimiento como parte de entierros y ofrendas en contextos protoclásicos y clásicos tempranos de sitios como Chiapa de Corzo sugiere un uso primario en la combustión ritual de ofrendas. Las sustancias quemadas pueden haber sido copal o alguna otra resina, textiles, papeles impregnados de sangre o animales pequeños, como aves o roedores (Lowe, s.f.: 66). Evidentemente, resulta necesario realizar un estudio más profundo de tales artefactos para comprender sus diversos usos sociales a través del tiempo.

Cuando San Lorenzo comienza a decaer y da inicio el Formativo Medio, los incensarios aumentan su popularidad en todo el occidente de Chiapas con la aparición de algunas formas nuevas. El brasero anular del Formativo Temprano se realiza ahora con bordes decorados y soportes interiores. Los incensarios en forma de cáliz aparecen tanto en Chiapas como en Puebla para esta época (Agrinier, 2000: 44, figuras 44a-44c; García Cook y Merino Carrión, 2005: 610, figura 14; Warren, 1961: 77), pero tal forma siguió en Chiapas por lo menos hasta el Protoclásico (Lowe, 1999: figura 11), un hecho que demuestra la continuidad de la identidad humana en Chiapas. Las versiones chiapanecas frecuentemente muestran modificaciones en el receptáculo en forma de ventilas así como soportes tabulares o asas de canasta. Tales rasgos se mantendrán por más de un milenio en Chiapa de Corzo y otros sitios del occidente de Chiapas, indicando así la coalescencia de una identidad social regional. Los incensarios de tres y cuatro picos huecos aparecen en Chiapa alrededor de 900 a.C. (Bachand et al., 2008: figura 95b; Lowe y Mason, 1965: figura 8). El ejemplar en forma de tecomate hallado durante la temporada 2008 (ver figura 5) recuerda algunos fragmentos de la fase Duende descubiertos en Izapa (Lowe et al., 1982: figuras 7.12c y 7.12d). Lowe, Lee y Martínez Espinosa $(1982: 123,127)$ pensaban que la fase Duende de Izapa correspondía a una intrusión cerámica y arquitectónica maya temprana llegada desde la mitad oriental de Guatemala, fuera del área mixe-zoqueana, 


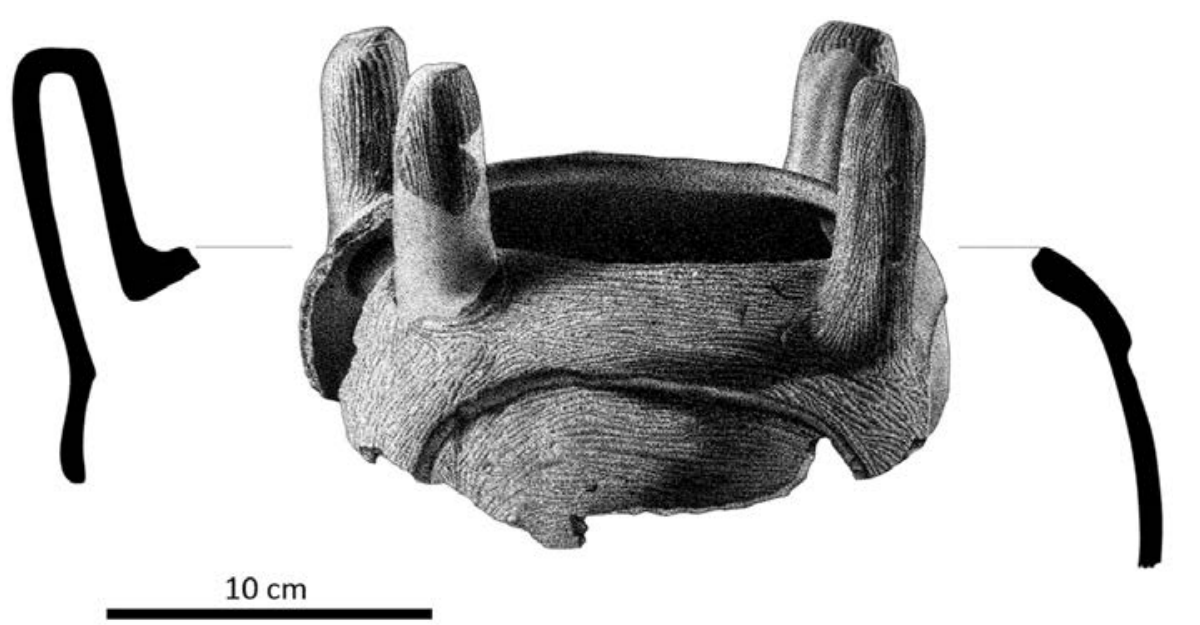

FIGURA 5. Incensario de cuatro picos procedente de un basurero Chiapa II-B atrás de la Estructura 1 (dibujo realizado por Áyax Moreno).

posiblemente de Takalik Abaj (Popenoe de Hatch, 2007: 168). Aunque muy tenue, ésta representa la única evidencia sugestiva de un origen maya para los incensarios de tradición zoque (Demarest, 1976: 86). Es importante destacar que los incensarios de tres picos no aparecen en La Libertad ni en otros sitios del oriente de la Depresión Central sino hasta la fase Chiapa III (Clark y Cheetham, 2005: 385). Las versiones orientales de esta forma, especialmente aquéllas conocidas como "ármelo usted mismo", con picos intercambiables o extraíbles, fueron inspirados en una notable tradición de las Tierras Altas mayas emanada desde Kaminaljuyú.

Apenas empezamos a entender la evolución genealógica entre las formas y modos de estos objetos especiales a través del tiempo y el espacio. El estilo básico de un plato puesto sobre un soporte alto, anular y abierto sin base continuó por siglos como la forma ideal. Sin embargo, vemos en sus embellecimientos los rasgos peculiares de tiempo y cultura. Por ejemplo, las lenguietas, cejas o aletas interiores que se pusieron en los braseros olmecas del Formativo Temprano continuaron en siglos posteriores como una sola añadidura en el centro del receptáculo. Especímenes con calado en los hombros o bordes y posiblemente también los ejemplos con asas de estilo canasta empezaron a aparecer en la fase Dili o Chiapa II-A. Asimismo, los braseros anulares con cuernos huecos llegaron a ser comunes en Chiapa II-A, cediendo el paso a cuernos sólidos en la siguiente fase Chiapa III y al fin de la fase a la forma mayense de "ármelo usted mismo". También, cuando empieza Chiapa III, los braseros anulares comenzaron a aparecer con pares de agujeros de ventilación geométricos practicados sobre las bases tubulares. Los braseros de este tipo se encuentran también en La Venta y Kaminaljuyú, pero ningún sitio parece haber tenido tal cantidad de ellos como Vista- 
hermosa, Mirador o Chiapa de Corzo. Los incensarios no resultaron ser comunes en la planicie de Tabasco como lo fueron en Chiapas durante el Formativo Medio Inferior (Sisson, 1976; von Nagy, 2003). No obstante, indicó Drucker (1952: 121) que fragmentos de los pot rests ocurrieron en la mayoría de los niveles de las calas estratigráficas en La Venta (las cantidades actuales no fueron reportadas). Sin embargo, en conformidad con las observaciones sucesivas de Sisson y von Nagy, Drucker mencionó que no tuvo conocimiento de objetos parecidos en otros sitios en la región. Entonces, es muy probable que los ejemplares que se han recuperado en La Venta estuvieran inspirados por la tradición zoque del occidente de Chiapas y tal vez no se originaron en La Venta.

Lo que me impresiona mucho como un fenómeno significativo es que no hubo ningún ejemplo de estos incensarios de supuesta función religiosa detectado en las ofrendas públicas olmecas de Chiapa de Corzo y San Isidro. Por cualquier razón, las ofrendas públicas de los gobernantes no incorporaron estos objetos tan emblemáticos de la identidad local zoqueana. Parece, entonces, que en caso de que los incensarios del Formativo Medio fueran objetos rituales, hubieran estado restringidos a usos domésticos. Por eso, el caso del basurero grande que excavó Lynneth Lowe atrás de la Estructura 1 en 2008 representa un hallazgo interesante (Bachand et al., 2008: figuras 19, 22, 23, 24, 95, 111 y 112a; L. Lowe s.f.). El basurero contuvo un incensario de cuatro picos, una figurilla hueca olmeca y vasijas bien hechas que pertenecen a la fase II-B —es decir, basura doméstica de una casa privilegiada.

Los reportes publicados sobre la cerámica Las Charcas de Kaminaljuyú no inspiran confianza en el supuesto origen maya de la tradición de incensarios de Chiapas. González y Wetherington (1978: 291, tabla 1) señalan que únicamente seis de 5000 fragmentos de incensarios recuperados durante las excavaciones de la Universidad Estatal de Pennsylvania pudieron ser asignados a la fase Las Charcas del Formativo Medio; de ellos, la mitad, es decir tres, correspondían a platos en forma de comal —una forma que aparece en la Depresión Central de Chiapas por lo menos un siglo antes (Lowe, s.f.). Los tres ejemplares restantes pertenecen a una tapa alargada de incensario, una vasija con borde modelado y un incensario de tres picos (los autores no mencionan los "mangos de incensarios con efigie" reportados por León y Valdés, 2002: figura 17.6 para la fase Las Charcas). Borhegyi (1951: 173) indicaba que estas tapas y los incensarios de tres picos eran las dos formas más comunes en las fases más tempranas de Kaminaljuyú. El incensario de tres picos surge en Chiapa de Corzo hacia la fase Chiapa II. Gareth Lowe y J. Alden Mason (1965: 212) alguna vez supusieron "un punto de origen en el sur de Guatemala o el occidente de El Salvador" para este tipo de incensario. Esto fue antes de que Coe y Diehl (1980, vol. 1: 152) reportasen un fragmento del Formativo Temprano procedente de San Lorenzo, y otros ejemplos tempranos fueron reconocidos posteriormente en Mirador, Vistahermosa y San Isidro. La reciente subdivisión estratigráfica de Las Charcas (ubicada por investigadores previos hacia 650 a.C.) en una segunda fase, más tardía, conocida 
como Majadas (Hermes y Velásquez, 1996; Velásquez, 1991), arroja serias dudas entre la contemporaneidad de los incensarios de tres picos de Kaminaljuyú con los de Chiapa II (Willey et al., 1964). La escasez de incensarios del Formativo Medio científicamente excavados en Kaminaljuyú y la reciente subdivisión de Las Charcas parece indicar que cierta cantidad de los incensarios clasificados originalmente por González, Wetherington, Borhegyi y otros son posteriores a la fase Las Charcas. Hermes y Velásquez (1996: 445) mencionan explícitamente la presencia de comales, tapas con agarraderas dobles e incensarios de tres picos en los depósitos Majadas. La fase Majadas es contemporánea con Escalera o Chiapa III de Chiapa de Corzo, e incluye cerámica anaranjada nebulosa negativa descrita por Wetherington. Ello significa que probablemente Las Charcas podría fecharse para la fase Chiapa II o II-B. Así, la fase cerámica más temprana de Kaminaljuyú, Arévalo (el equivalente a Chiapa I-B), debería contener algunos incensarios, si se considerara que la tradición del Altiplano guatemalteco fuese tan antigua como los ejemplos de la Depresión Central. Durante Arévalo, sin embargo, podríamos estar tratando con una ocupación cultural de Kaminaljuyú influenciada por los mixezoques costeños; y esta situación podría haber sido extensiva en todos los sitios del Formativo Temprano a lo largo de la Sierra Madre y la Costa Pacífica desde el oriente de Oaxaca hasta El Salvador.

En síntesis, la tradición mesoamericana de incensarios parece haber tenido su origen entre los mokayas hablantes de mixe-zoque de la fase Locona (preolmeca) del Formativo Temprano, hacia 1400 a.C. Al iniciarse el periodo Formativo Medio, dos culturas, los zoques del occidente de Chiapas y los mayas del Altiplano de Guatemala, desarrollaron una notable predilección por tales objetos. Los zoques parecen haber sido los primeros en desarrollar esta tradición, al emerger de una base ancestral mixe-zoqueana alrededor del 900 a.C. La tradición maya de incensarios de las Tierras Altas florece casi un siglo después, hacia el 800 a.C. irradiando algunas formas distintivas, como la de "ármelo usted mismo", hacia los zoques del oriente de Chiapas por el año 600 a.C. El hecho de que ambas regiones compartiesen formas básicas de incensarios produciendo miles de ellos a lo largo de varias generaciones, sugiere que ambas culturas formativas compartían una relación común, aunque diferenciada, con los mixe-zoques -y digo esto porque los sitios como Chiapa de Corzo y Kaminaljuyú tenían poco en común durante Chiapa II, precisamente cuando sus respectivas tradiciones de incensarios cristalizaron. Los habitantes de Tabasco durante el Formativo Medio no muestran la misma afición por los quemadores de incienso; el pequeño número que aparece en esta región recuerda a los ejemplares del occidente de Chiapas y podría ser parte de la revitalización de la zona nuclear olmeca producida, en parte, por una diáspora mixe-zoque, ahora hablantes de zoque. Los mayas de las Tierras Bajas parecen haber hecho casi ningún uso de los incensarios en esta época. Las regiones ubicadas al oeste y al norte, como Oaxaca, Morelos, Puebla, Guerrero y el centro de México desarrollaron sus propias tradiciones con menor intensidad a partir de la segunda mitad del Formativo Medio. 


\section{Chiapa II-B (Dili Tardío)}

La fase Chiapa II-B (aproximadamente entre 850-750 a.C.) atestiguó la dispersión del plan MFC de los sitios y su arquitectura monumental a través del occidente de Chiapas (Lowe, s.f.). La construcción más temprana que descubrimos dentro del Montículo 11 —una plataforma piramidal que alcanza una altura de $4.5 \mathrm{~m}$ - se fecha a esta fase (unos 35 de los 754 tepalcates que salieron del relleno de dicho edificio estuvieron identificados con certeza como tipos Chiapa II-B). Esta construcción pública es igual en antigüedad, o incluso un poco anterior, a cualquier edificio monumental registrado hasta el momento en La Venta. Los edificios de arcilla hallados dentro de los Montículos 11 y 12 representan el conjunto tipo E más temprano documentado arqueológicamente a la fecha en la Depresión Central de Chiapas (Mason, 1960: 2, para la evidencia del Montículo 12). Sospechamos que el sitio de Finca Acapulco, ahora inundado por los aguas de la Presa Angostura, contuvo un grupo tipo E que era más temprano que el de Chiapa de Corzo. Investigadores del INAH encontraron una profusión de tepalcates Chiapa II en las superficies de dichos montículos y también en sondeos cercanos (Gussinyer, 1972; Lowe, 1977: figura 9.4; 1991: 115; s.f.: 51). Respecto a este importante descubrimiento se deben mencionar cuatro cosas: (1) que el trabajo aconteció años antes de que miembros de la NWAF empezaran a identificar los modos diagnósticos de Chiapa II-B en la Depresión Central, (2) que las excavaciones no fueron de suficiente profundidad para probar los rellenos interiores de dichos montículos, (3) que la cerámica Chiapa I fue abundante en el sitio y en aquel sector del Río Grijalva y (4) que parece que hubiera sido una cancha de juego de pelota que estaba asociada en algún momento temprano con el grupo de conmemoración solar/astronómica. En conformidad con los datos disponibles, parece muy posible que los grupos de conmemoración solar/astronómica se originaran en la región Mazatán durante el undécimo siglo antes de Cristo (véase la discusión en Bachand y Lowe, 2012).

Finalmente, nos preguntamos si las ofrendas masivas de hachas depositadas al pie del Montículo 11, asignadas con base en buenas evidencias cerámicas a la fase Chiapa III, no podrían ser contemporáneas a las famosas ofrendas de hachas de San Isidro. Gareth Lowe (1981) originalmente fechó los depósitos de hachas de San Isidro para Chiapa III, pero posteriormente reasignó su cronología para Chiapa II-B con base en un único pozo de sondeo realizado en el sitio cercano de El Laurel (Lee, 1974: 6; véase la explicación en Lowe, 1998: 52). Esta comparación puede ser interpretada desde tres perspectivas históricas: (1) que las ofrendas de hachas de Chiapa de Corzo sean ligeramente posteriores a las de San Isidro, (2) que ambos sitios sean contemporáneos, pero que la cerámica Nicapa aparezca antes en la Depresión Central que en el Grijalva Medio o (3) que la asignación original de las ofrendas de San Isidro correspondientes a la fase Equipac fuese la correcta. Si hubiese que apostar por alguna de estas opciones, me inclinaría por la segunda, pero en la actualidad no tenemos forma de establecer cuál fue la situación concreta. 
Lo que complica comparaciones entre sitios es la diversidad cerámica que caracteriza los complejos Chiapa II-B. Cada sitio tiene diferentes tipos y modos que son suficientemente parecidos, aunque distintos en sus expresiones locales - lo cual indica un paisaje diverso probablemente habitado por entidades políticas independientes aunque étnicamente homogéneas. En agosto de 2012 tuve la oportunidad de examinar las colecciones II-B de la NWAF y definir, por primera vez, una fase II-B para Chiapa de Corzo que designo con el nombre "Dzemba" y que está compuesta de nueve tipos (tres son recién descritos) y una gran cantidad de modos. Los contextos controlados del Montículo 11 y el basurero del Área A resultaron críticos para definir esta fase transicional.

\section{El renacimiento de la fase Escalera (ca. 750/700 a.C.)}

Antes de comenzar los trabajos de la temporada 2008 existía una amplia evidencia que indicaba que Chiapa de Corzo había experimentado un notable renacimiento cultural durante la fase Escalera o Chiapa III. El plan del sitio MFC fue completado con la adición de los Montículos 13 y 17, y se había descubierto el elaborado entierro de una supuesta dignataria olmeca del Golfo en una plataforma baja en el núcleo del Montículo 17 (Cheetham y Lee, 2005; Clark, 2000; Lee, 1969). Se detectaron también varias plataformas de arcilla de posible función residencial en una ubicación central debajo de los Montículos 1A y 7 (Agrinier, 1975; Lowe, 1962: 45). Timothy Sullivan (2009) descubrió asimismo una marcada nucleación de las poblaciones del hinterland en la zona cívica de Chiapa de Corzo. Nuestro registro de los profundos rellenos culturales excavados detrás de la Estructura 1 reveló el alcance del importante programa de obras públicas que extendió la orilla sur de la gran plataforma ceremonial por medio del relleno parcial de una antigua barranca (Bachand et al., 2008). Todos estos hallazgos implican la existencia de una sociedad jerárquica en creciente desarrollo. Aun considerando esto, los descubrimientos realizados en el Montículo 11 resultaron bastante sorprendentes.

\section{La tumba del Montículo 11}

La tercera versión del Grupo tipo E fue el lugar escogido para los eventos ceremoniales que dieron forma a la identidad política y étnica de los chiapacorceños en los siglos por venir. El basamento piramidal Chiapa II-B del Montículo 11 fue elevado hasta una altura de $6.5 \mathrm{~m}$ para contener la tumba de un poderoso dignatario y su consorte en la cima, y una serie de extraordinarias ofrendas de hachas fue depositada dentro de la roca madre en la plaza a sus pies (figura 6). El examen preliminar de los objetos hallados en la tumba y en los pozos de ofrenda sugiere una contemporaneidad con las ofrendas de las fases II-III de La Venta (ca. 800-700 a.C.). Este tercer episodio constructivo coincide así con los primeros complejos de conmemoración de las Tierras Bajas mayas. 
El personaje central de la tumba era un hombre de edad adulta (figura 7). Un segundo personaje de la élite, una mujer adulta, fue localizado también en un anexo de la cripta. Casi 3000 ornamentos de jade fueron hallados como parte del ajuar funerario de ambos individuos, que incluían diminutas perlas, conchas, pirita, hematita y ámbar. Los restos de varias máscaras fueron hallados en la tumba, y ambos personajes tenían espejos cuadrados de placas de pirita con restos del estuco que recubría la base. Dos de las paredes de la tumba fueron construidas con lajas de piedra natural, e inferimos que las otras dos se mezclaban con el compacto relleno de arcilla que formaba el núcleo de la pirámide. Un techo y una tarima de planchas de madera sellaban el interior de la tumba que contenía al personaje principal y a sus dos acompañantes. Los rumbos cardinales estaban marcados por hachas de andesita —en el mismo estilo de las hachas rituales que se encontraron en abundancia en las ofrendas de la plaza. Dieciocho vasijas cerámicas, algunas de la fase Chiapa II-B, acompañaban a los fallecidos (figura 8).

Una descripción detallada de la tumba aparece en otras publicaciones (Bachand y Lowe, 2011; 2012). Aquí simplemente quisiera destacar ciertos elementos que pueden iluminar la imagen histórico-cultural del sitio y la región.

Sobre la boca de ambos personajes fueron colocadas conchas marinas. Lynneth Lowe destacó el hecho de que la colocación de una concha bucal en los entierros fue una práctica repetida en muchas tumbas de élite posteriores en Chiapa de Corzo y San Isidro (Lowe y Agrinier, 1960: figuras 45, 48 y 49; Lowe, 1999: figuras 33-35). Otra observación realizada por Lowe fue que la alternancia de paredes de lajas y arcilla era una característica constructiva típica de las tumbas del Formativo Tardío y el Protoclásico en el sitio. Así, la tumba del Montículo 11 representa la instauración inicial de rasgos que posteriormente definirían las costumbres funerarias zoques en el occidente de Chiapas.

Es preciso llamar la atención acerca de algunas características de los rasgos olmecas de los collares y adornos que portaban los personajes de la tumba. El collar del dignatario estaba compuesto por casi un millar de cuentas de jade que incluían 17 plaquitas talladas en forma de concha de almeja. El collar de la señora llevaba 24 cuentas en forma de cabeza de pato, cormoranes y otras aves acuáticas. Tanto las conchas como los patos representan elementos comunes en el repertorio artístico olmeca del Formativo Medio. Aunque el hallazgo de tan abundantes ejemplos de delicado trabajo artesanal en un solo contexto arqueológico resulta raro, y tal vez sin precedentes, éstos aparecen claramente ligados a los extendidos cánones mesoamericanos de inspiración olmeca. Otros ejemplos aislados, o de ejecución menor, han sido encontrados en La Venta (Drucker, 1952: láminas 54d y 58). Las cuentas de jade de los cinturones presentan semejanzas con La Venta. El pendiente central del señor, un perro con largo morro, y el par de calabacitas que portaba la señora, resultan similares a algunas piezas encontradas en diversas ofrendas en La Venta (Drucker, 1952: láminas 52, 57Ap y 57Aq). 


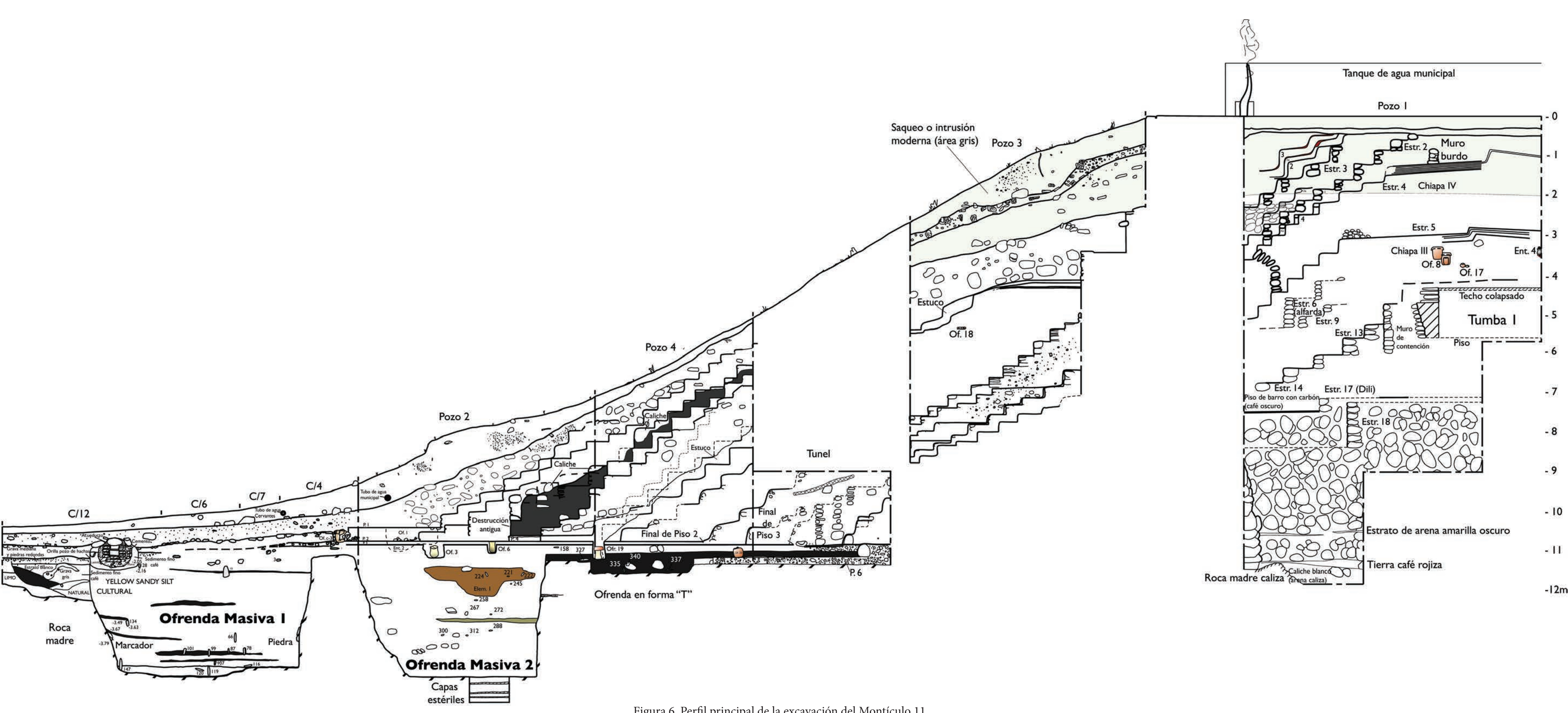




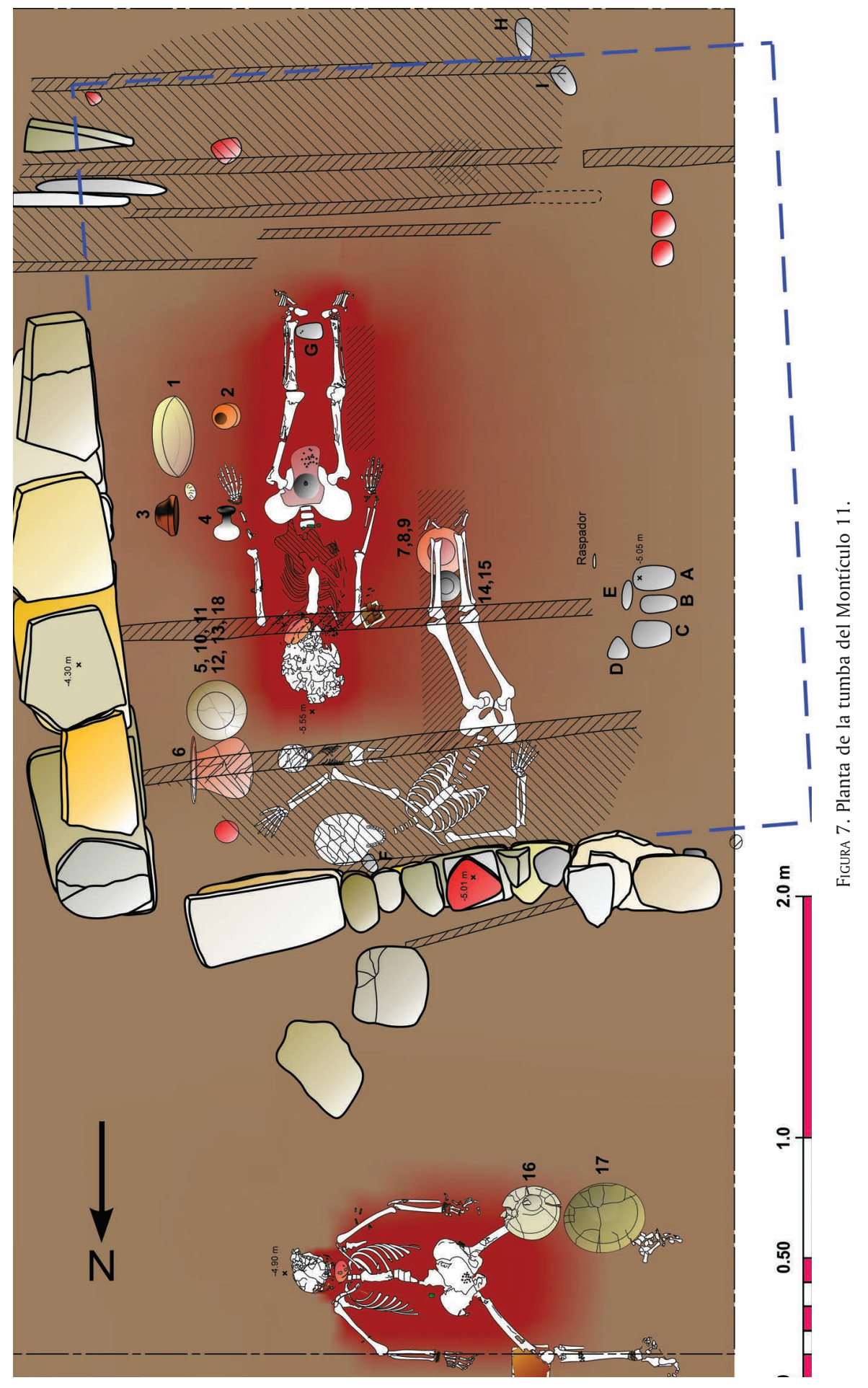



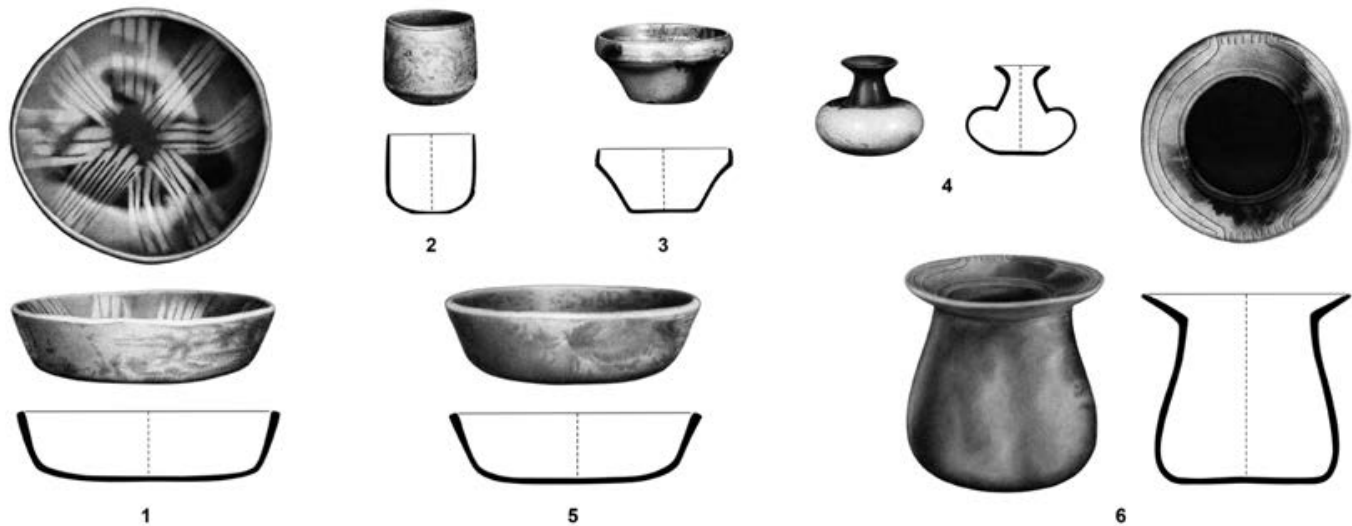

2

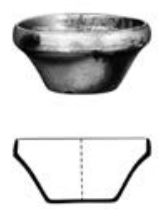

3
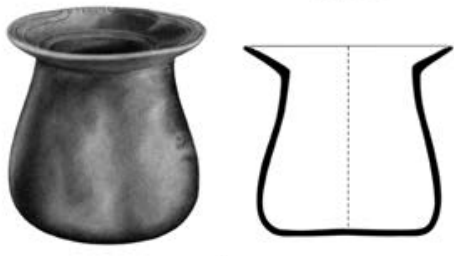

5

6
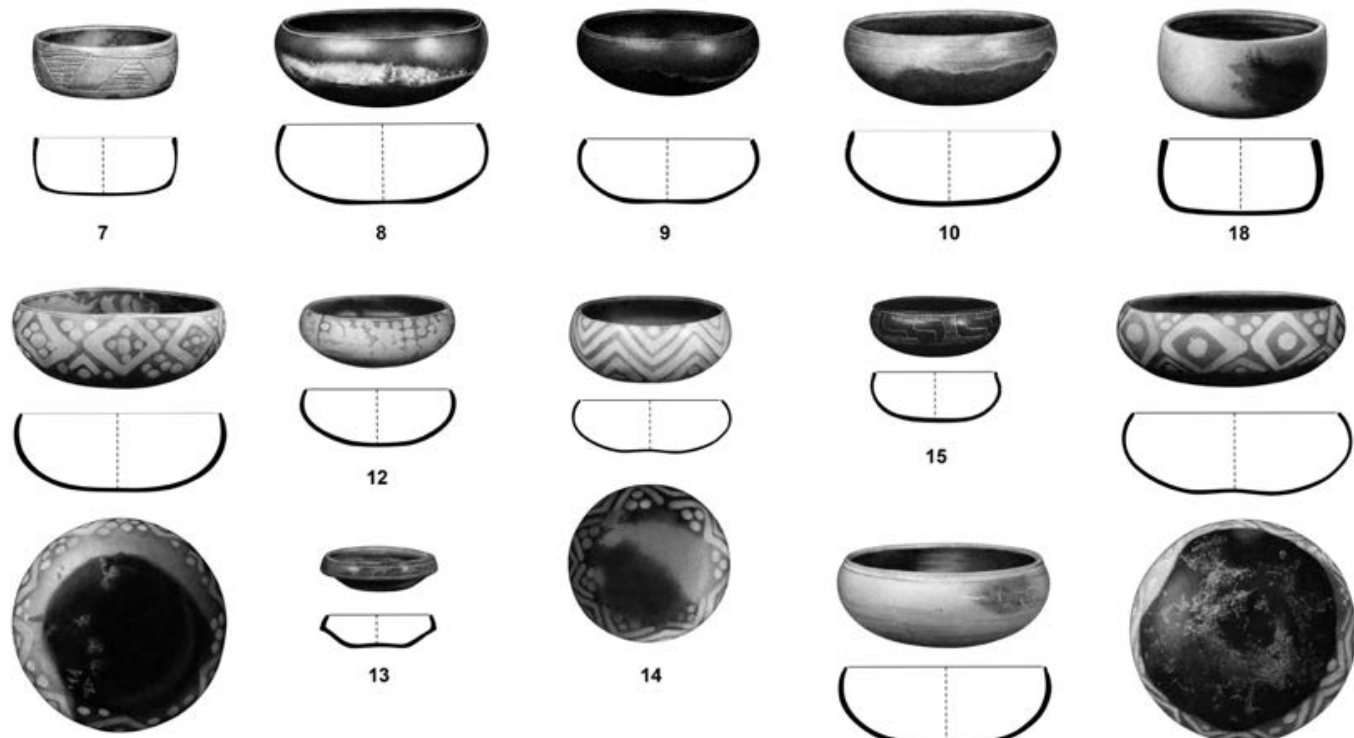

11
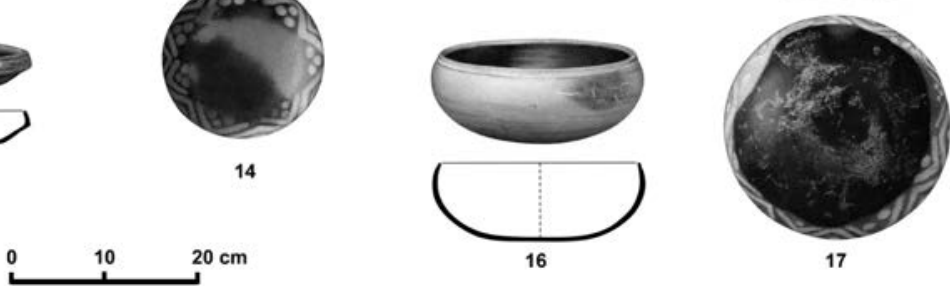

Figura 8. Vasijas funerarias de la Tumba 1, Montículo 11. 
Otros objetos de la tumba no tienen comparación. Los espejos cuadrados de placas de pirita resultan singulares para este horizonte cronológico, al igual que las diminutas cuentas metálicas, probablemente también de pirita, de $20-40 \mathrm{~mm}$ de diámetro que daban un destello dorado a los ornamentos de jade y perlas. Las cuentas tubulares de ámbar también son únicas. La materia prima podría haber sido obtenida a unos 30-80 km al norte en las Tierras Altas de Chiapas (L. Lowe, 2005: 47), o alternativamente, unos $35 \mathrm{~km}$ al este en la Depresión Central cerca de Totolapa (10 km noreste de Acala), donde se ha encontrado evidencia de ocupación formativa alrededor de un yacimiento importante de ámbar y un material asociado, el lignito o carbón fósil conocido localmente como azabache (Bryant, 2004; Lee, 1993: 232 y 2004).

Las 18 vasijas del ajuar funerario implican una serie de preguntas acerca de su producción, intercambio y origen de formas específicas de la cerámica del Formativo Medio. Como se ha mencionado, la mayoría parecen ser transicionales de la fase Chiapa II a III — tal vez reliquias de familia con origen en Chiapa II-B. Un solo cajete Nicapa Naranja-negativo con bordes convergentes representa el único ejemplo claro de Chiapa III. Un pequeño plato Llomo Café también podría ser de esta fase, pero es preciso recordar que este tipo nebuloso aparece en depósitos Chiapa II-B en Mirador, por lo que se ha propuesto que puede ser regionalmente un "prototipo del Nicapa Naranja-negativo" (Agrinier, 2000: 67; notado por Warren, 1961: 78). Ambas vasijas y un plato burdo sin duda proceden de la región. Las otras 14 resultan más difíciles de asignar. Nueve de los cajetes corresponden por su cocción diferencial o decoración ahumada a las fases Puente Tardío hasta Franco Temprano (800-550 a.C.), con formas de cuencos redondeados comunes en Tabasco (Pohl, 2005; von Nagy, 2003; Drucker, 1952: láminas 19a y 19b). La mayoría presenta pasta gris a negra sin desgrasante o con desgrasante de ceniza volcánica. Dos ejemplos de pasta gris muestran un tacto de pizarra en sus superficies pulidas y otros cuatro llevan diseños al negativo sobre sus superficies cubiertas con engobe blanco ahumado. Otro de ellos, un cajete negro ahumado con diseños incisos y punzonados zonales resulta idéntico a los tiestos Chiapa II-B/III hallados en Mirador y Vistahermosa (Agrinier, 2000: figura 62; Lowe, s.f.: figura 12).

Todas estas vasijas, especialmente la última, podrían ser reconocidas normalmente como importaciones de la costa del Golfo (Agrinier, 2000: 62; Cheetham y Lee, 2005: figuras 14 y 24; Drucker, 1952: lámina 20; Lowe, s.f.: figura 12; von Nagy, 2003: 650). Sin embargo, no concuerdo totalmente con esta conclusión por las siguientes razones: (1) la cerámica con desgrasante de ceniza volcánica fue ampliamente producida en tiempos Chiapa III; el tipo diagnóstico del periodo, Nicapa Naranja-negativo, frecuentemente tenía desgrasante volcánico y una pasta de grano fino (Warren, 1961: 78; observaciones personales); (2) la cerámica ahumada con engobe blanco y elaborados diseños negativos, aunque escasa, está ampliamente documentada para Chiapa de Corzo y Mirador (Agrinier, 2000: figura 54; Cheetham y Lee, 2005: figura 17), pero resulta inexistente en la costa 


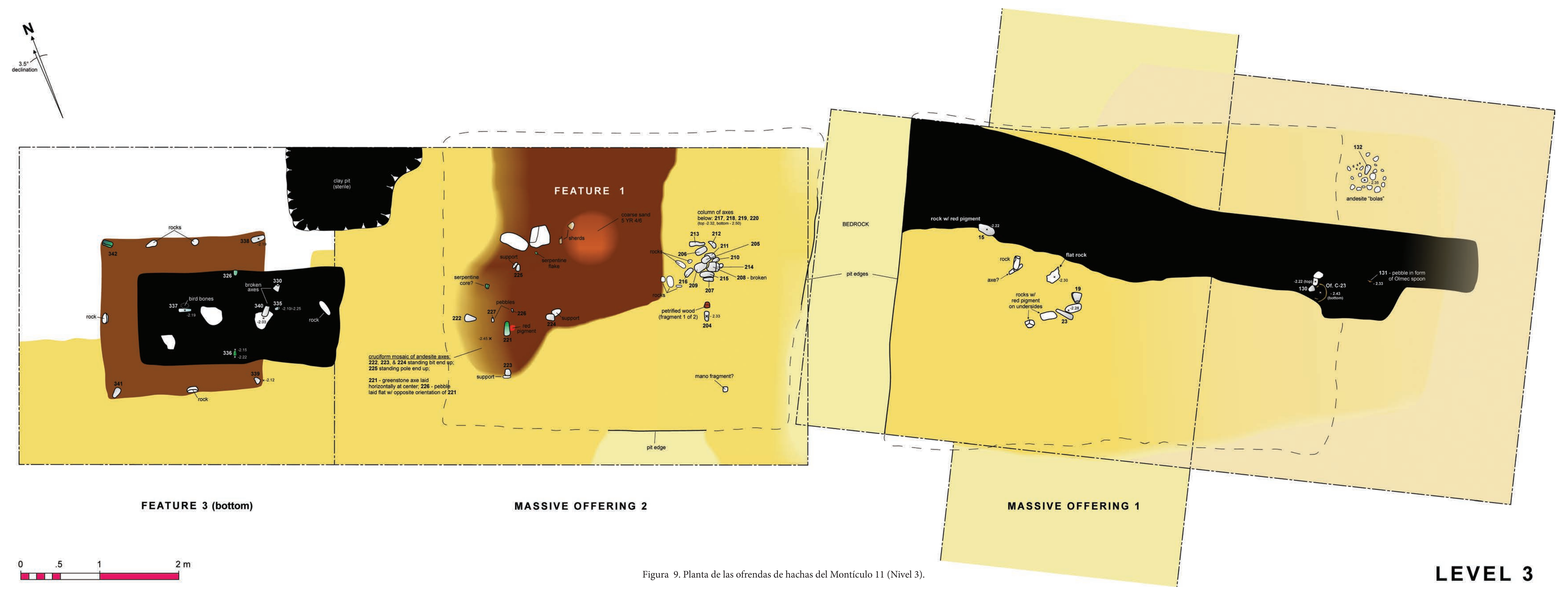


del Golfo (por supuesto que esto puede deberse a las malas condiciones de preservación de la región); (3) la cerámica negativa era más apreciada en Chiapas que en la zona nuclear olmeca del Golfo, lo cual tiende a sugerir un lugar más cercano de origen; (4) los tipos negros incisos y punzonados son "relativamente raros" en Tabasco (von Nagy, 2003: 597), y, finalmente, (5) la cerámica de pasta gris también resulta escasa en Tabasco y los tipos sin desgrasante se restringen a la fase Franco Tardía (ca. 500-300 a.C.) en aquella región (von Nagy, 2003: 204, 211). Dejando de lado estas consideraciones, las últimas cinco vasijas — una urna con doble línea quebrada sobre el borde evertido, una ollita blanca de cuello alto, un pequeño cuenco de engobe anaranjado, un cajete con triángulos incisos y un plato grande de base plana y diseños negativos de líneas en el fondo- parecen ser de origen foráneo, aunque esto deberá ser comprobado a través de cuidadosos análisis comparativo, petrográfico y químico.

\section{Las ofrendas de hachas del Montículo 11}

Gracias al apoyo adicional de la National Geographic Society y de la Fundación Arqueológica Nuevo Mundo tuvimos la posibilidad de documentar un extraordinario elemento ritual a los pies del Montículo 11. Aquí fueron depositados al interior de la roca madre, en alineación con el eje principal de la pirámide, dos pozos masivos de ofrenda y un pozo somero en forma de un occupied bracket (Joralemon, 1971: figura 77), que en conjunto contenían un total de 339 hachas ceremoniales aparte de los otros objetos rituales. La estratigrafía, la cerámica y las ubicaciones relativas de los artefactos implican que estas ofrendas fueron depositadas en un solo esfuerzo coordinado a principios de la fase Chiapa III. El evento, localizado en el centro simbólico de la ciudad, parece haber bautizado a Chiapa de Corzo como una potencia regional (Bachand y Lowe, s.f.). Podría decirse que esta validación pública fue exhibida con nuevos propósitos cosmológicos, refiriéndome en concreto a las hachas, aunque otras hachas similares fueron encontradas en el relleno estructural de la fase II-B de este montículo. El hacha representaba ya un símbolo cultural. La novedad consistía en la manera en que las hachas eran elaboradas, colocadas y, tal vez, reconceptualizadas por la población local.

Los depósitos contenían una amplia variedad de formas de hachas, desde aquellas elaboradas de manera experta hasta las seudohachas mínimamente modificadas, y los cantos rodados y rocas naturales. La mezcla de niveles de ejecución implicada por tales piezas sugiere la inclusión de adeptos y no especialistas, quienes pudieron haber seleccionado y colocado las rocas en los pozos. La calidad de "industria doméstica" de muchos de los objetos distingue a las ofrendas de hachas de Chiapa de Corzo de aquellas registradas en La Venta, El Manatí, La Merced y aun San Isidro. No obstante, debemos enfatizar tanto el considerable reconocimiento espacial como el conocimiento ritual (y tal vez astronómico) y la 
planificación que condujeron el proceso de deposición de los objetos y la división de los espacios. Evidentemente, ello representó un complejo esfuerzo colectivo.

Cada ubicación ritual difería en su disposición, contenido y función. Los tres pozos de ofrendas fueron alineados de este a oeste, con el pozo en forma de un occupied bracket ubicado en la base de la pirámide y la Ofrenda Masiva 1 localizada en el extremo oriente hacia la plaza (figura 9). Cada pozo presentaba un arreglo cruciforme de hachas a la misma profundidad sobre el eje principal (figura 10). Estas ofrendas contenían hachas pulidas de piedras finas - jadeíta, serpentinita, albita y esteatita-, incluyendo un hacha de serpentina con la imagen grabada de una deidad olmeca (figura 11). Este último ejemplar fue colocado de pie junto con un hacha de jade verde esmeralda, con la imagen sagrada hacia la cara de la pirámide (Bachand et al., 2008: figura 73).

Las Ofrendas Masivas 1 y 2 fueron localizadas en pozos excavados de aproximadamente $4.0 \times 6.0 \mathrm{~m}$ en planta. Fueron ejecutados en la roca madre a $3.5 \mathrm{~m}$ de profundidad separados por una sección de $1 \mathrm{~m}$ de ancho de roca madre. La alternancia de niveles de artefactos y suelos de colores (amarillo, negro y café) fue cuidadosamente arreglada desde el fondo hasta la cima. Ambas ofrendas tuvieron once estratos reconocibles por la presencia o ausencia de artefactos.

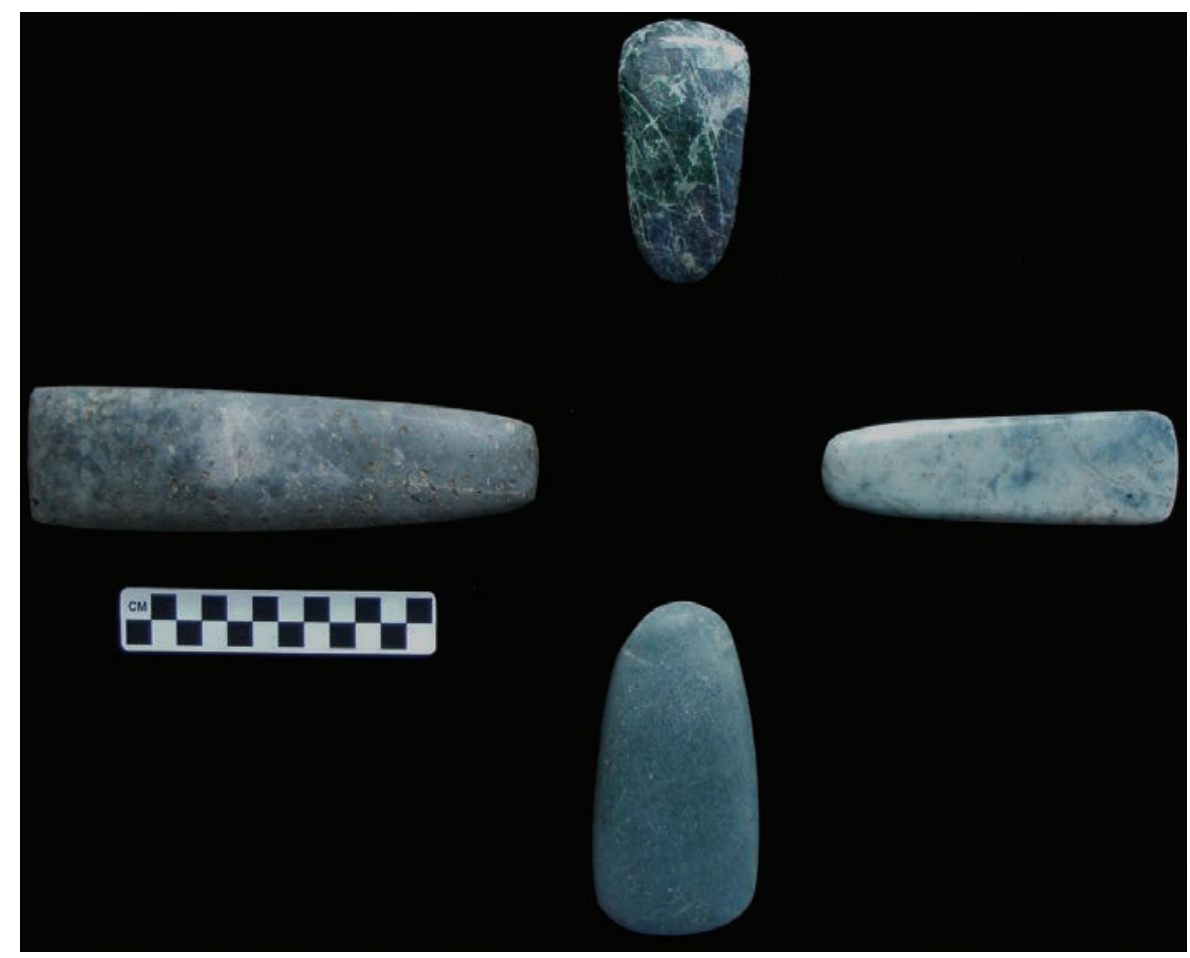

Figura 10. Hachas y "celtas" halladas al centro del mosaico en forma de un occupied bracket. 

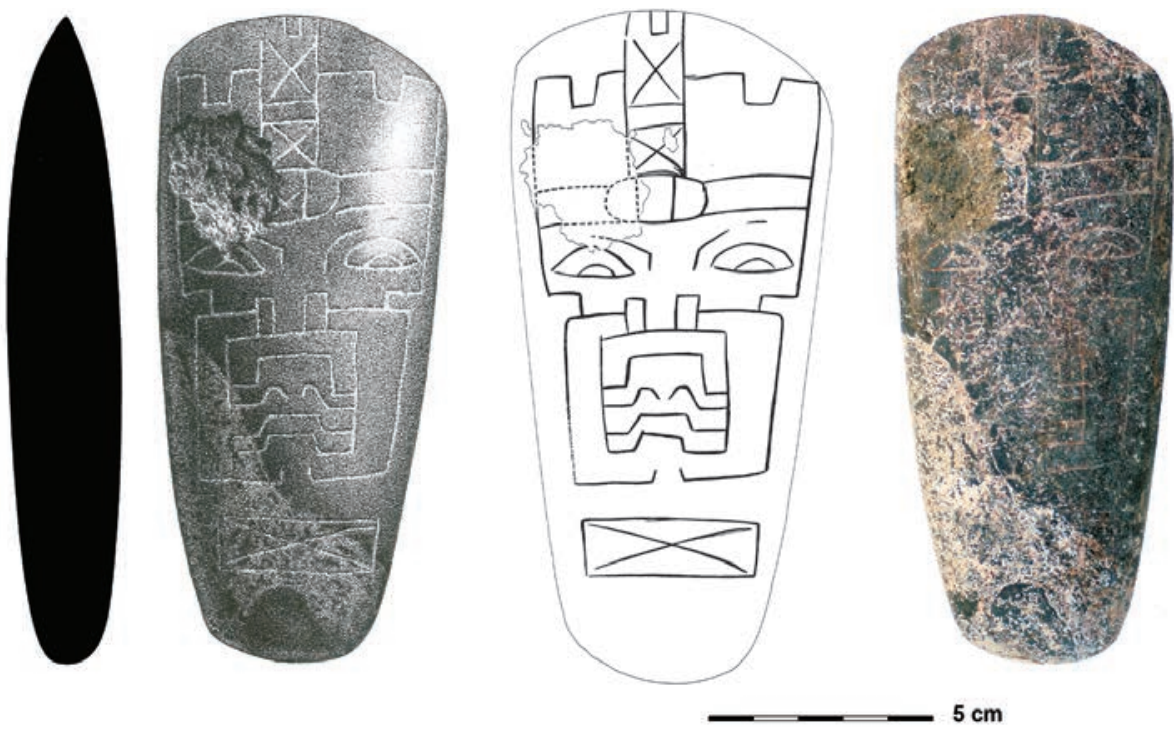

Figura 11. Hacha de serpentina incisa con una deidad olmeca (dibujo realizado por Áyax Moreno).

La Ofrenda Masiva 1 se caracterizó por patrones lineales, alineados direccionalmente, de hachas colocadas en forma vertical u horizontal. Las hachas verticales fueron colocadas en agujeros circulares en las cuatro esquinas y el centro de cada lado al fondo del pozo. El estrato medio del pozo contenía el elaborado entierro sacrificial de un adulto varón joven de procedencia local (figura 12; análisis osteológico realizado por Andrés del Ángel, de la UNAM, y de estroncio por Carolyn Freiwald, de la Universidad de Wisconsin en Madison). Al igual que las vasijas de la tumba, las cuatro piezas encontradas con este individuo implican una atribución cultural ambigua. La vasija en forma de caracol y la ollita parecen formar un conjunto similar a otro par equivalente registrado en La Venta (Drucker, 1952: 70; Bachand et al., 2008: 140). La composición de las pastas, sin embargo, recuerda mucho a la cerámica gris con desgrasante de hornablenda de la fase Dili, sugiriendo una imitación local de un concepto cultural extendido, posiblemente aristocrático. Sus formas, decoración y contextos las distinguían como piezas especiales. Colocados con el difunto también se encontraron (1) un par de orejeras rústicas y pesadas que fueron talladas de una piedra verde, (2) un pendiente tubular hecho de serpentina negra, (3) una concha bivalva pequeña y (4) tres pequeños cantos de río bien pulidos y de color verde - uno en forma de hacha. Faltaron los huesos del pie y de la mano del esqueleto.

La Ofrenda Masiva 2 no se parecía a nada documentado previamente para un sitio olmeca. Era un pozo de ofrenda donde se incluyó también desecho de producción lítica (275 piedras/núcleos, 926 lascas que juntas son iguales a 1201 piezas o $545 \mathrm{~kg}$ de material). John Clark y el autor empezaron a analizar dicho material, y 


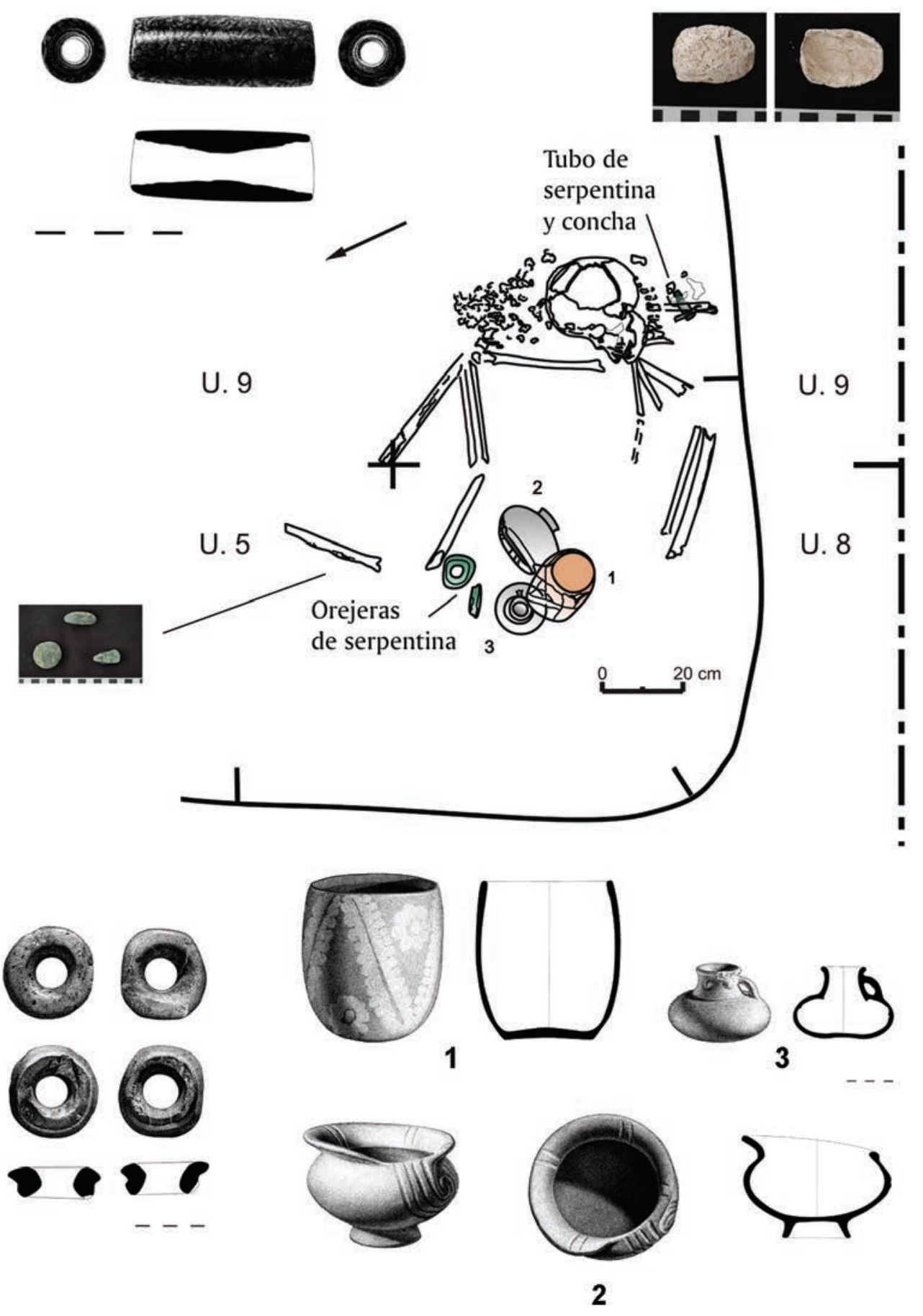

Figura 12. Entierro C-1 de la Ofrenda Masiva 1

(dibujos de artefactos realizados por Áyax Moreno). 
se puede concluir de manera provisional que no estaba asociado con la producción de las hachas que hemos registrado en las ofrendas. Originalmente, el autor pensó que tal vez se trataba del desecho que resultó de la producción de las hachas expeditivamente hechas de materiales locales — por ejemplo, dolomita, caliza y piedra arenisca-, que estuvieron ampliamente representadas en la Ofrenda Masiva 2. Cuando fue evidente que no era así, de acuerdo con la pequeña cantidad de escombro que resultó de las experimentaciones de replicación que hizo Clark, consideramos la posibilidad de que este material resultara de la producción de diferentes objetos, tal vez picas para excavar la roca madre. Sin embargo, cuando empezamos a examinar las lascas y a unir algunas de ellas con núcleos, esta hipótesis tampoco fue viable. Al contrario, parece que dicho material estuvo asociado con un comportamiento ritual que todavía no entendemos bien. Es claro que los creadores quebraron algunas piedras por medio de levantar rocas muy pesadas, de unos 30 a $50 \mathrm{~kg}$, y dejándolas caer verticalmente sobre otras para efectuar lascas grandes y planas, una técnica claramente bipolar que exigió fuerza y precisión considerables. No se halló ningún desecho de manufactura relacionado con las hachas de andesita o piedra verde - no cabe duda de que estas fueron elaboradas con mucho cuidado y tiempo en algún otro lugar. Algo interesante es que se utilizó el escombro en una manera simbólica, colocando lascas, núcleos, percutores, preformas, etc., en lugares específicos dentro del pozo. También encontramos piedras grandes y planas con canales que posiblemente resultaron del pulimiento de los filos de las hachas (figura 13); uno de ellos mostraba la forma de un hacha.

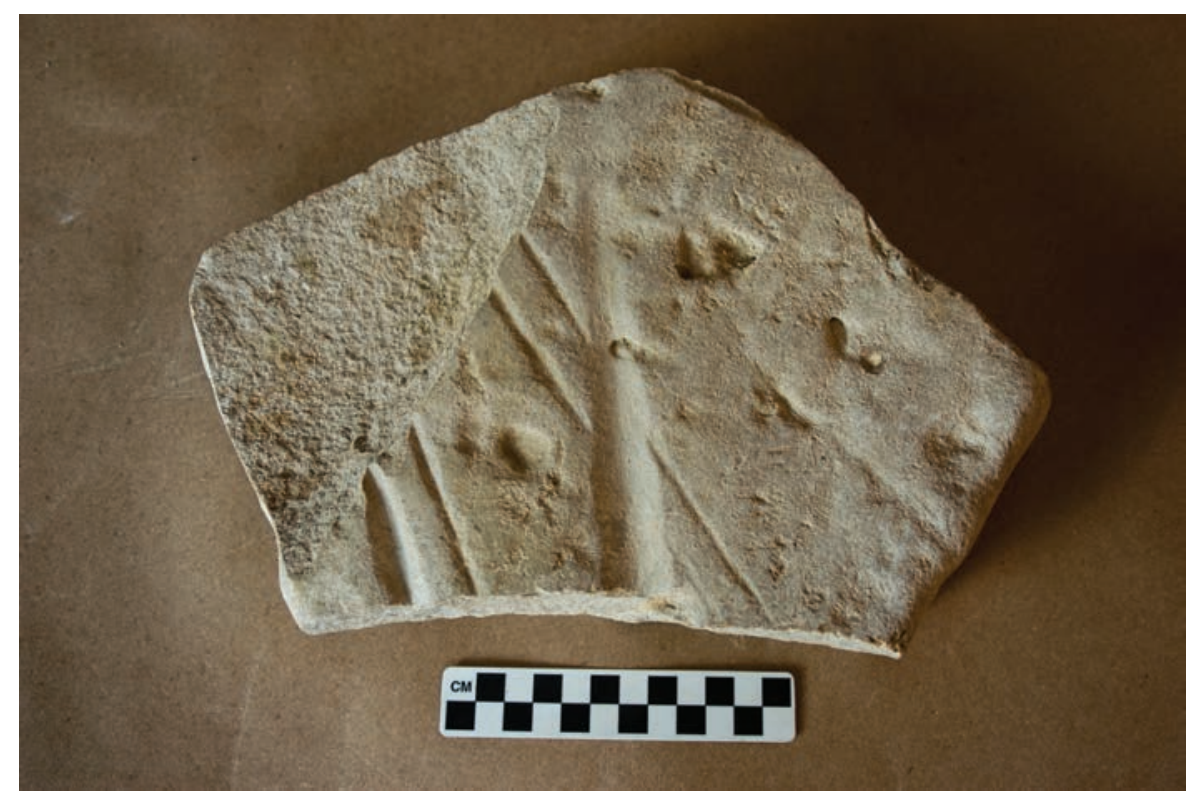

FIGURA 13. Piedra plana y dura que se utilizó para moler, pulir y afilar las hachas. 
El pozo en forma de un occupied bracket estaba obviamente compuesto por dos elementos diferentes. Un pozo de color café rojizo con seudohachas verticales fue penetrado por otro pozo rectangular de color café oscuro que contenía un arreglo cruciforme de cuatro hachas de piedras finas de colores diferentes: dos "celtas" en el eje este-oeste y dos hachas en el eje norte-sur. Un conjunto de tres seudohachas de andesita fue colocado al oeste en una depresión de la roca en el eje principal del mosaico justamente bajo su orilla este. Este arreglo fue sellado con sedimento amarillento, barro negro del pantano y un elemento peculiar: un par de muros en forma de L de una sola hilada que formaban un borde sobre la ofrenda. En el arte olmeca tales elementos comúnmente se hallan en pares con cruces que representan en forma esquemática la hendidura de la cual surgen las plantas de maíz o el axis mundi (Joralemon, 1971: 69; Taube, 1996).

El mosaico previamente descrito parece haber sido la tapa simbólica de las ofrendas masivas de hachas. Estaba asociado a una serie de vasijas que sugieren la realización de una celebración o bebida ritual. En el centro del área fue depositado un gran contenedor de cerámica en forma de barril, que no contenía ningún objeto. Lo mismo sucedió con la docena de vasijas colocadas al este del pozo. También se hallaron tres vasos superpuestos al oeste del eje que dividía las paredes de piedra, sin artefactos en su interior, aunque uno de ellos contenía pigmento rojo. Las muestras recolectadas del fondo nos ayudarán a determinar su contenido, que probablemente eran bebidas como pozol, cacao o cerveza de maíz. Después de la celebración toda el área fue sellada con piso duro de caliza compacta, cuya construcción fue contemporánea con la tumba antes mencionada.

\section{Origen y dispersión de la cerámica Nicapa Naranja-negativa}

Los eventos anteriores representaron una nueva época para Chiapa de Corzo y alteraron en forma dramática el paisaje político de la región. En ese momento, estaban surgiendo una docena de centros poderosos en la Depresión Central (Lowe, 1977: 222-228). Todos ellos compartían un plan formado por "una plataforma piramidal y una plaza formal", que ahora es conocido como el plan tipo Chiapas del Formativo Medio o MFC (Clark y Hansen, 2001: 4). Un elemento importante en este renacimiento fue el amplio consumo de las vasijas de servicio de acabado naranja negativo o nebuloso designadas colectivamente como tipo Nicapa Naranja-negativo por Bruce Warren. Gareth Lowe consideraba a Nicapa como un "tipo fósil" (Lowe, 1978: 366), expresando que:

[...] el patrón de distribución de la gran tradición cerámica del Anaranjado nebuloso negativo es uno de los mejores argumentos para la continuidad y expansión de la comunidad zoqueana a lo largo periodo Preclásico Medio (Lowe, 1977: 224).

Después de 50 años de reconocimiento constante, esta cerámica clave ha sido finalmente descrita de manera formal por Clark, Cheetham, Miller y otros (Clark y 
Cheetham, 2005: 379; Miller et al., 2005: 142). Tales descripciones han resultado invaluables para apreciar la presencia local de Nicapa en Chiapa de Corzo y evaluar la extensión y temporalidad de la influencia zoque en las regiones vecinas.

Se han propuesto dos inferencias histórico-culturales cruciales sobre Nicapa por parte de Clark y otros: 1) que Nicapa aparece desde 750/700 a.C. en la Depresión Central, y 2) que esta cerámica se origina en la parte media de la Depresión, en la zona ahora sumergida aledaña a los sitios de Finca Acapulco, Vergel y San Mateo. Si ello es correcto, significa que Nicapa sería originario de esta región y que su historia de distribución duraría casi cuatro siglos, desde 750 hasta 400 a.C. Dicho argumento servía para neutralizar las hipótesis anteriores de un origen salvadoreño o maya para este tipo (Andrews, 1990: 13-14; Demarest, 1976: 87, 97).

Desafortunadamente, la evidencia de radiocarbono que se utiliza para situar el límite temprano de Nicapa en 750/700 a.C. está plagada de problemas. La fecha temprana se basa en la precisión de un solo resultado en una serie de cinco determinaciones pre-AMS de Montículo 27 de Mirador (Agrinier, 2000: 35-36). Las muestras de carbón se obtuvieron de cuatro construcciones sobrepuestas de las fases Chiapa III o Quequepac, pero el resultado más temprano — para el cual se confía en fechar el comienzo de Chiapa III- se asoció con la última construcción entre las cuatro que se fecharon. Agrinier descartó los otros cuatro resultados como "muy recientes" para sus contextos en las primeras tres etapas de construcción Quequepac dentro del Montículo 27, pero no ofreció ninguna explicación de por qué podría ser el caso. Suponiendo que las fechas están invertidas, nos quedamos con una determinación de potencial precisión, I-6222, derivada de un poste quemado que se encontró en la plataforma de las Estructura Q4. Sin embargo, como una fecha del Formativo Medio solitaria, este ensayo es de valor limitado. Aunque la relación contextual de la muestra es excelente y es probable que el intervalo entre el evento fechado y el evento arqueológico sea pequeño, el ensayo es sólo exacto en menos de 400 años debido a la trayectoria horizontal de la curva de calibración a lo largo de la ignominiosa Meseta Hallstatt que coincide con la Edad de Hierro de Europa y el Formativo Medio de Mesoamérica entre 800 y 400 a.C. Para complicar las cosas, ninguna edad sin calibrar a.p. o valor $\delta 13 \mathrm{C}$ fue presentada por Agrinier (y por alguna razón, el laboratorio Teledyne no informó los resultados en la revista $R a-$ diocarbon). En resumen, el límite inferior de Chiapa III en la Depresión Central se basa en una sola fecha incorrectamente informada y de validez cuestionable. En el análisis final, la fuerza de la fecha propuesta de 750 a.C. deriva de las comparaciones puntillosas de la cerámica y la estratigrafía de Agrinier en lugar de las pruebas de radiocarbono. Es este preciso asunto, la transición a Chiapa III, que los hallazgos recientes del Montículo 11 de Chiapa de Corzo refieren directa y abundantemente. No hay ninguna fecha de radiocarbono que pertenezca a las épocas Chiapa II o III en los sitios de Finca Acapulco o San Isidro - un hecho que aumenta la importancia de las fechas cronométricas anticipadas de Chiapa de Corzo. 


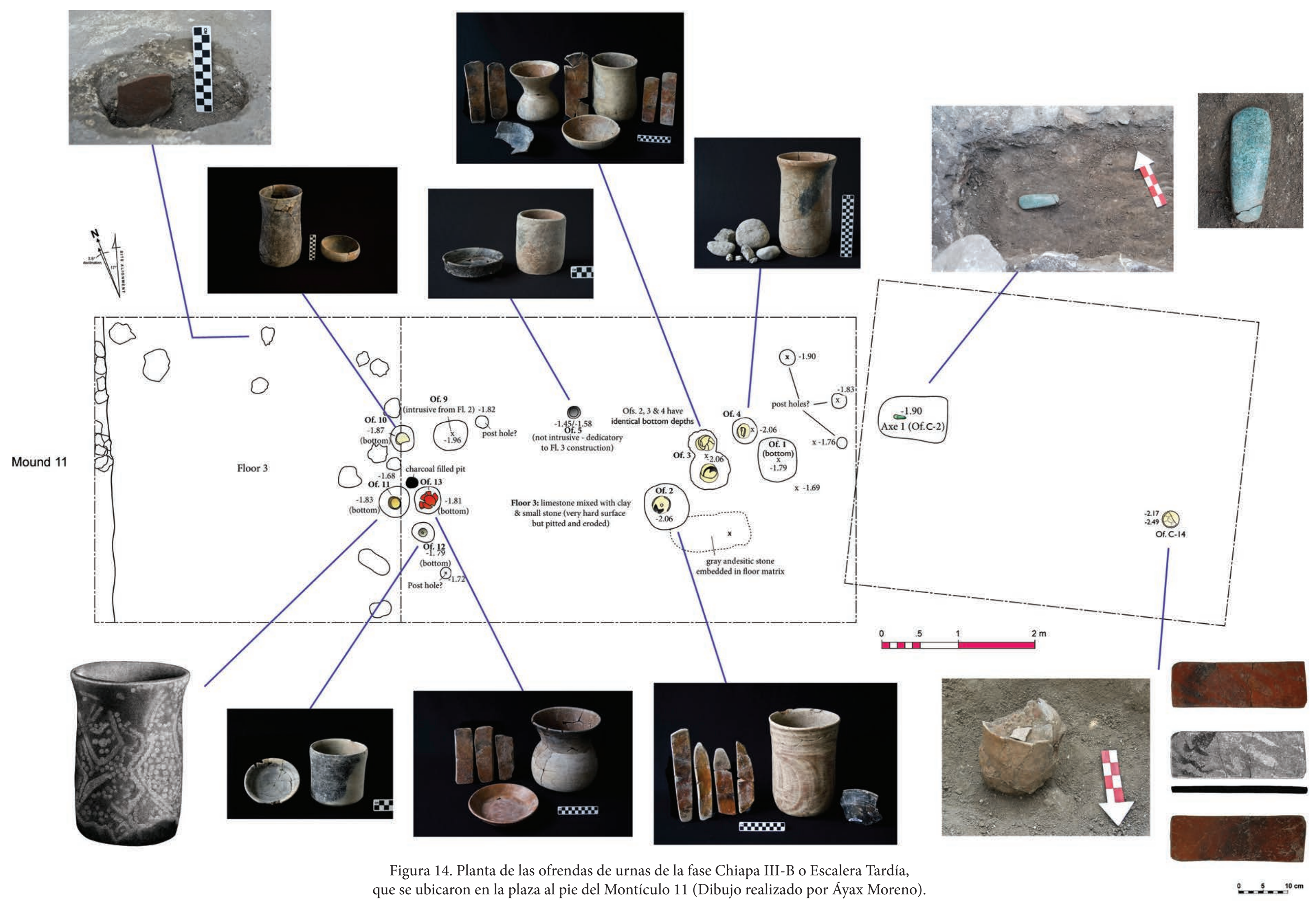


Para continuar con otros asuntos, yo sugeriría una posible variante temporal y/o regional para Nicapa, de acuerdo con los resultados de las excavaciones recientes en Chiapa de Corzo, el examen de las vasijas completas en el Museo Regional de Chiapas, el estudio de la notas no publicadas de Bruce Warren y el manejo comparativo de las colecciones tipológicas de los muestrarios de la Fundación Arqueológica Nuevo Mundo en San Cristóbal de las Casas. Parece ser que las variedades Rodeo Patterned y Enguti Inciso de Nicapa son raras y tardías en Chiapa de Corzo. Rodeo, especialmente, podría ser diagnóstica de una faceta tardía de Chiapa III. Ambas variedades y ciertos modos, como los diseños de medio círculo de Enguti, son más comunes en las colecciones del Alto Grijalva (Miller et al., 2005: 146, 169, llegan a una conclusión similar). Uno podría pensar que esto indica un periodo mayor de gestación para el tipo en el oriente, pero los ejemplares del occidente de Chiapas son más tempranos, evolucionando en conjunto y emergiendo de tipos de Chiapa II-B como Llomo Café (véase arriba la discusión de la tumba). Alternativamente, las variedades Rodeo y Enguti pueden representar otra línea de evidencia para una separación cultural o política entre las mitades oriental y occidental de la Depresión Central en la segunda mitad de Chiapa III entre 600 y 400 a.C. La cerámica negra cerosa, Libertad Negro-Café y Chunhinta Negro de las Tierras Bajas mayas, también resulta ser más abundante y diversa (incluyendo modelado, incisiones, etc.), en las colecciones de La Libertad. Otros elementos como la famosa doble línea quebrada de Dili podrían ser más comunes en el occidente. Las cuatro construcciones superpuestas de Chiapa III en el Montículo 11 proporcionan una excelente oportunidad para establecer la frecuencia de tales atributos en Chiapa de Corzo.

La cronología, ubicación y cantidad de la cerámica naranja negativa fuera de la Depresión Central permitirá entender las relaciones entre la sociedad zoque y sus vecinos. Tabasco y La Venta resultan particularmente interesantes al respecto. Este tipo es virtualmente inexistente en la mayoría de las aldeas tabasqueñas (von Nagy, 2003), pero fue importado en menores cantidades hacia 500 a.C. en sitios de élite, como La Venta y San Andrés (Lowe, 1978: 372; Pohl, 2005). La cerámica Mamom exhibe el mismo patrón en Tabasco, pero parece ser un par de siglos anterior y algo más común (Pohl, 2005). Con base en esta evidencia, parecería que Chiapa de Corzo y la Depresión Central tuvieron un contacto limitado con La Venta para los inicios de Escalera, idea sustentada por el descubrimiento ocasional de monumentos y objetos portátiles olmecas. Lo que tal evidencia sugiere es que La Venta no estuvo, al menos completamente, ocupada por pueblos zoques (Clark, 2000). Por el contrario, los datos actuales suponen que La Venta era una ciudad cosmopolita y multiétnica, tal vez la segunda gran aparición del fenómeno de mestizaje olmecoide (Clark, 1993: 50-52), pero esta vez incluyó pueblos distantes como los mayas. En realidad, el patrón de Nicapa Naranja en La Venta no es muy diferente del que se observa en Laguna Zope (Zeitlin, 1979: 20), un sitio dentro de una región que era mixe para este periodo y casi sin presencia de cerámica naranja negativa (véase la discusión de Chiapa II-B arriba). Un modelo de unidades políticas equivalentes, o sea, peer polities, podría ser aplicable en ambos casos. Sin embargo, este modelo 
no concuerda bien con los vecinos orientales de los zoques, los mayas. En sitios como Izapa, La Lagunita y aun Kaminaljuyú, la cerámica naranja negativa comprende una porción significativa del complejo cerámico. ${ }^{2}$ Los complejos Mamom de la región del río de la Pasión estuvieron fuertemente dominados por las vasijas cerosas de color naranja-rojizo o café manchado (Adams, 1971; Bachand, 2006 y 2007; Sabloff, 1975). Parece así que ambas regiones, maya sureña y zoque, tuvieron un contacto más fluido y amplio durante Chiapa III — promovido, posiblemente, por el surgimiento de La Libertad, que, como sabemos, fue un punto importante en el comercio de la obsidiana de San Martín Jilotepeque (Clark, 1988).

\section{Una fase tardía de Escalera o Chiapa III-B}

Una de las mayores sorpresas al excavar el Montículo 11 fue el descubrimiento de un basamento piramidal de la fase Escalera Tardía que contenía un elaborado entierro, indudablemente otra tumba, colocada debajo de su superficie (Bachand y Lowe, 2011). La estratigrafía demostró que las urnas de ofrenda y una gran hacha de jade (Ofrenda C-2) colocadas en la plaza eran también contemporáneas de esta fase (figura 14). La treintena de vasijas del entierro y la plaza mostraban atributos que no permiten ubicarlas fácilmente en las fases Escalera o Francesa (figuras 14, 15 y 16). Una de las vasijas del entierro, una olla de doble cámara con vertedera, asa de canasta y la imagen modelada de un enano (figura 15), recuerda bastante la vasija silbadora negra del Entierro 2 del Montículo 7 (Lowe, 1962: figura 28, lámina 25a1). Lowe (1962: 45) mencionaba que este entierro y los Entierros 1, 4, 5 y 6 fueron "colocados tardíamente en la secuencia constructiva de 7-E”. Al consultar la tesis doctoral de Bruce Warren (1978: 185-189) y sus notas no publicadas se puede apreciar que el Entierro 2 y su contenido fueron considerados como pertenecientes a una fase Escalera Tardía. En esta labor para subdividir la fase Escalera, Warren describió y clasificó provisionalmente tal vasija como Soyaló Modelado-Inciso.

Se debe explicar con más detalle por qué este descubrimiento constituyó una revelación importante y bienvenida, si no es que sorpresiva. Después de excavar extensivamente la plaza del Cuadrante Suroeste durante 2008, varias observaciones me llevaron a pensar que Chiapa de Corzo pudo haber estado abandonada para el final del periodo Formativo Medio, al mismo tiempo que La Venta. Yo consideré que tal inferencia estaba razonablemente sustentada en la estratigrafía, la cerámica, la obsidiana, las antiguas fechas de radiocarbono y los patrones de asentamiento regional, y aun así la noción de una ocupación "reducida” ha sido considerada por décadas (Lowe y Mason, 1965: 212; Warren, 1978). La idea, presentada públicamente en el Congreso Internacional de Americanistas en 2009, fue tomada con escepticismo.

\footnotetext{
${ }^{2}$ Sin embargo, véase León y Valdés, 2002: 384 para una caracterización de Kaminaljuyú que es similar a lo que describo para La Venta y Laguna Zope, pero con un desafío a la fase Majadas.
} 

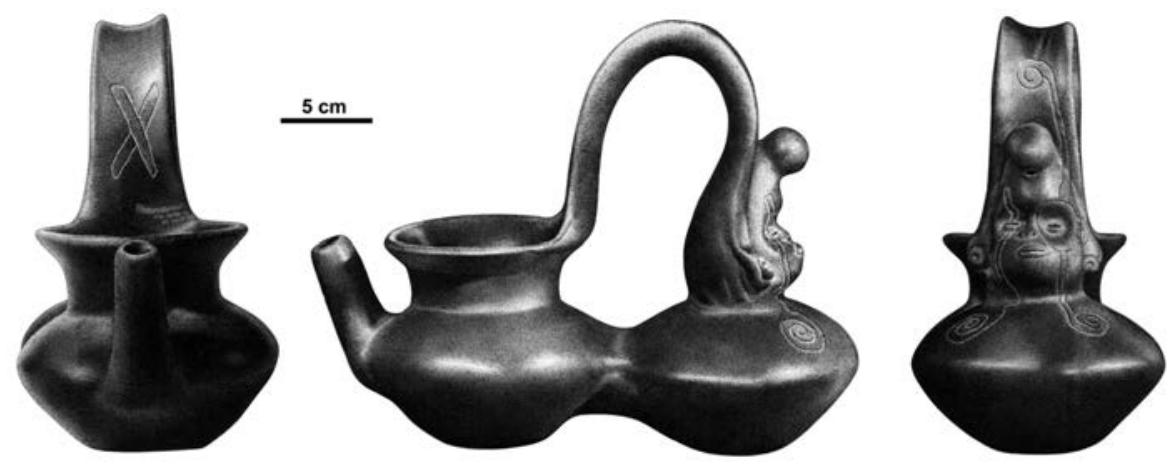

Figura 15. Vasija de doble cámara con espiga, asa de canasto y cara modelada de un enano. Entierro 4, Montículo 11 (dibujo realizado por Áyax Moreno).

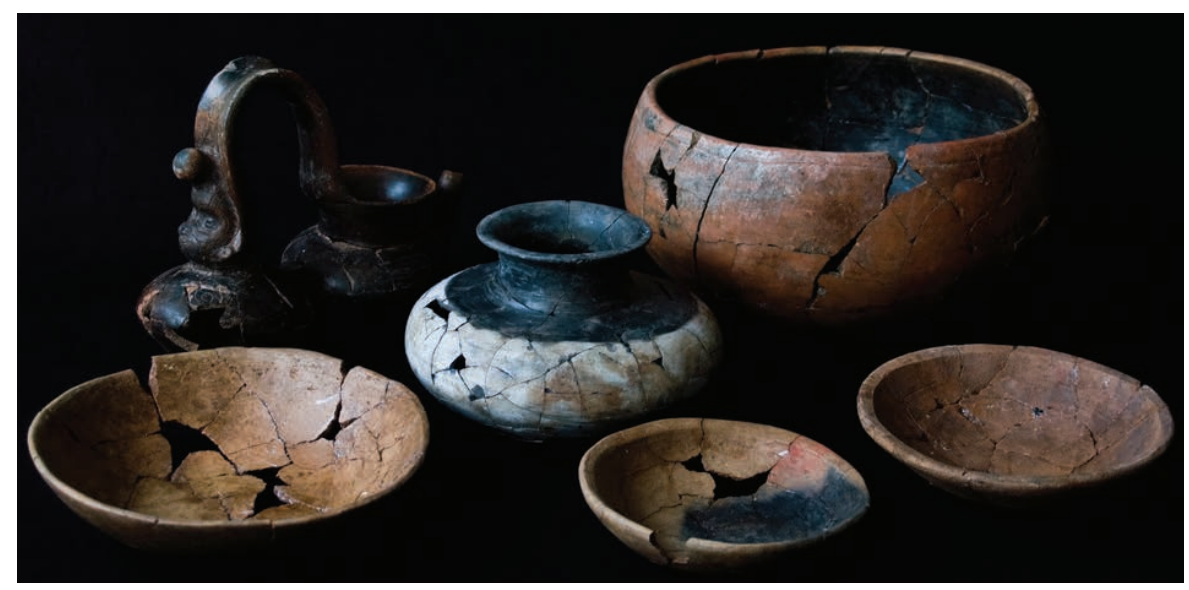

FiguRA 16. Vasijas funerarias del Entierro 4, Montículo 11.

Las ofrendas de urnas cilíndricas del Montículo 11 merecen una comparación más cercana con las ofrendas de la fase Felisa de San Isidro, al pie del Montículo 20 (Lowe, 1999: 56-66). Las ofrendas de ambos sitios ofrecen una interesante muestra del ritual zoque del periodo Formativo. Los ejemplos de Chiapa de Corzo se derivan de pozos intrusivos realizados en la superficie de las ofrendas masivas (figura 14). La estratigrafía y evidencia cerámica indican que el primer piso que hubo sellado los pozos masivos se erosionó en la antigüedad y la gente de Chiapa III-B la cubrió de nuevo con un piso macizo de estuco y tierra antes de colocar la mayoría de las ofrendas de urnas. Dichas urnas son muy notables por su contenido, consistente en placas cerámicas alargadas, algunas de las cuales presentan forma de hacha. Las placas fueron cortadas y pulidas de las bases de grandes platos de servicio tipo Nicapa. Algunos presentaron marcas y huellas de rayado en sus 
caras. Cinco urnas contenían un total de 13 placas. Varias depresiones circulares penetraron en la superficie de la plaza cerca de estas urnas. Son bastante someras y ubicadas al azar, pues no muestran ningún patrón espacial como sería de esperar para agujeros de poste, y una de ellas tenía un tiesto plano con lineas rayadas que seguramente resultaron del uso, plantado en posición vertical (figura 14). Aunque no es una evidencia firme, podría sugerir que los hoyos fueron utilizados para colocar las placas de cerámica en posiciones rectas sobre el piso, y el contexto y fecha del Formativo Medio Tardío sustentan tal propuesta.

Los hallazgos del Montículo 11 y las notas de Warren presentan una manera promisoria para subdividir la fase Chiapa III en Chiapa de Corzo, otorgando así un nexo cronológico necesario con la fase Francesa. Warren y Lowe iniciaron esta tarea al identificar los Entierros 1, 2, 3, 4 y 5 del Montículo 7 como Escalera Tardío. A dicha lista puede agregarse el Entierro 4 del Montículo 11 y las Ofrendas C-6, C-11, C-12, C-13 y C-14 de la temporada 2008, así como las Ofrendas 2, 3, 4, 5, 6, $7,8,11,12,17$ y 19 de 2010. A este grupo pueden sumarse los tres entierros de la fase E del Montículo 1A (Entierros 179, 180 y 181), que se introdujeron dentro de una construcción previa de las misma fase (Agrinier, 1975: 5). Uno de ellos, el Entierro 180, tuvo una vasija de tipo Rodeo Patterned-Negativo. Tanto algunos entierros y ofrendas del Montículo 17 (Lee, 1969) como el Entierro 20 y la Ofrenda 36-1 de Montículo 36 (Lowe, 1962: 59, lámina 29f, 29f', 29g, 29g1 y 29g2) tal vez puedan ubicarse en esta división de Escalera. Un grupo de urnas descubiertas en el Montículo 5b son también sospechosamente parecidas a las urnas IIIB documentadas en el Montículo 11 (Agrinier, 1964: figura 44; Lowe, 1962: 43, figura 23b, placa, d, d2 y d3). De un entierro del mismo montículo, las puntas que fueron esculpidas a partir de bases de vasijas cerámicas muestran la misma técnica de producción que observamos en las placas de Montículo 11 mencionadas en el párrafo anterior (Agrinier, 1964: figura 52; Lee, 1969: figura 56).

Entre febrero de 2011 y agosto de 2012 tuve la oportunidad de llevar a cabo un inventario tipológico de cerca de 48000 de los 68000 tiestos procedentes del relleno del Montículo 11. Durante dicho estudio, reconocí la presencia de nuevos modos y tipos cerámicos en los rellenos Chiapa III Tardío y Francesa. Descubrí muchos tiestos que muestran los mismos rasgos que se ven en las vasijas del Entierro 4 (figura 16). Es evidente que algunas de las diferencias no se restringen al nivel modal, sino que pertenecen a tipos que no caben bien en categorías tipológicas previas. Por lo menos, identifiqué tres tipos distintos: (1) cajetes o cuencos bien pulidos con baño delgado y horizontalmente rayado de color crema o claro sobre un barro naranja-café, (2) ollas pequeñas ahumadas con engobe blanco pálido y pasta café, (3) cajetes con paredes delgadas y verticales con un engobe mate naranja-rojizo que seguramente no son Mundet Rojo, y posiblemente un cuarto tipo: cajetes pulidos o con engobe negro-café con zonas punzonadas en su exterior. En resumen, noté rasgos distintos en tipos todavía no identificados que obviamente eran intermedios o transicionales entre Chiapa III y IV — un descubrimiento que claramente indicó una continuidad ocupacional 
en el sitio entre el transcurso del Formativo Medio y Tardío. Aunque se espera la confirmación cronométrica, calculo que dichos tipos fueron puestos en circulación entre los años 550 y 400 a.C. La predilección por cerámica negativa, líneas dobles preincisas, urnas altas, cajetes globulares, ollitas, engobes lechosos y mate, y cerámica punzonada parece ser común en esta faceta que nombro provisionalmente "Etzpa".

\section{Reubicando Francesa}

Dos razones para proponer el abandono a fines de Chiapa III fueron la falta de cerámica de la fase Escalera en la plaza del Cuadrante Suroeste en los niveles Francesa, así como la incongruencia entre las vajillas domésticas de Escalera y Francesa (Bachand et al., 2008: 149-150). Además, los objetos de estilo olmeca ocasionalmente hallados en contextos Francesa me parecían siempre de estilo Epi-Olmeca y algo fuera de lugar para el Formativo Medio o la faceta temprana (400-300 a.C.) del Formativo Tardío. Estas sospechas fueron confirmadas por la recalibración de dos fechas de radiocarbono publicadas para Francesa. La calibración actual dio un rango de 2-sigmas de 403 a 2 años cal a.C., un rango que alcanza cerca de 250/200 a.C. (Lowe y Mason, 1965: 215-216). La fecha 250 a.C. permite comparaciones materiales con regiones vecinas, pero crea otro problema: una falta de continuidad con la fase Escalera previa, que ahora se considera que inicia cinco siglos antes, hacia 750/700 a.C.

Con estos temas en mente, intentamos reubicar Francesa durante 2008. Dos fechas AMS de huesos largos humanos del cementerio Francesa frente al Montículo 1 produjeron resultados casi idénticos, $2155 \pm 48$ a.p. y $2158 \pm 36$ a.p. Al ser calibradas, ambas se ubican en 250 años calibrados a.C., coincidiendo con las de 1950 (las fechas fueron, por supuesto, tomadas de las muestras de mejor calidad). Tenemos ahora fechas muy adecuadas para este cementerio, un rasgo que probablemente corresponde al medio de Francesa. Ahora necesitamos confirmar a qué parte de la fase pertenece el cementerio con las fechas pendientes del Montículo 11. Por lo menos dos construcciones de la fase $\mathrm{F}$ fueron edificadas sobre el basamento Etzpa del Montículo 11. Se recuperaron algunos restos humanos articulados en los rellenos más tempranos de esta fase, y seguramente los huesos darán oportunidad de fechar construcciones con razonable confianza y esclarecerán la cronología de elementos como los elaborados entierros del Montículo 17 (Lee, 1969) y de San Agustín (Navarrete, 1959).

\section{Conclusiones}

Aunque resultan tentativas, nuestras cronologías cerámicas todavía no son lo suficientemente finas para responder a muchas de las cuestiones planteadas. Sin 
embargo, algunos temas de interés arqueológico, como la naturaleza de la sociedad temprana de Chiapa de Corzo, están saliendo a la luz. Como antropólogo, mi curiosidad radica en destacar una cultura poco conocida y muy negada, la zoque, y ponerla en discusión. Las grandes cuestiones que resultan de importancia para descifrar la identidad humana, como la influencia o la interacción entre grupos, pueden ahora ser estudiadas con más precisión que antes debido a los avances recientes en los métodos arqueológicos y en el trabajo persistente de las cronologías cerámicas regionales. Espero que estos hallazgos y observaciones recientes de Chiapa de Corzo apunten hacia una manera más segura y coherente de comprender el pasado de Chiapas.

\section{Agradecimientos}

Quisiera expresar mi agradecimiento al Centro de Estudios Mayas del Instituto de Investigaciones Filológicas de la UNAM por la invitación a participar en el Ciclo de Conferencias sobre Arqueología de Chiapas llevado a cabo a finales de 2010. Muchas inferencias valiosas se derivaron de la discusión académica establecida con los colegas mexicanos, guatemaltecos, norteamericanos e italianos durante los días del evento. Especialmente, deseo dar las gracias a Lynneth S. Lowe por su constante ánimo y paciencia, por su desempeño profesional y por la acuciosa traducción de este texto.

\section{BIBLIOGRAFÍA}

Adams, Richard E. W.

1971 The Ceramics of Altar de Sacrificios. Cambridge: Harvard University (Papers of the Peabody Museum of Archaeology and Ethnology, 63).

Agrinier, Pierre

1964 The Archaeological Burials at Chiapa de Corzo and Their Furniture. Provo: Brigham Young University (Papers of the New World Archaeological Foundation, 12).

1975 Mound 1A, Chiapa de Corzo, Chiapas, Mexico. Provo: Brigham Young University (Papers of the New World Archaeological Foundation, 37).

1984 The Early Olmec Horizon at Mirador, Chiapas, Mexico. Provo: Brigham Young University (Papers of the New World Archaeological Foundation, 48).

2000 Mound 27 and the Middle Preclassic Period at Mirador, Chiapas, Mexico. Provo: Brigham Young University (Papers of the New World Archaeological Foundation, 58).

Andrews V, E. Wyllys

1990 "Early Ceramic History of the Lowland Maya", Vision and Revision in Maya Studies, pp. 1-19, F. Clancy y P. D. Harrison (eds.). Albuquerque: University of New Mexico Press. 
Bachand, Bruce R.

2006 "Preclassic Excavations at Punta de Chimino, Peten, Guatemala: Investigating Social Emplacement on an Early Maya Landscape", tesis de doctorado en Antropolgía. Tucson: University of Arizona.

2007 "The Preclassic Ceramic Sequence of Punta de Chimino, Peten, Guatemala”, Mayab, 19: 5-26. Madrid: Sociedad Española de Estudios Mayas.

Bachand, Bruce R. y Lynneth S. Lowe

2011 “Chiapa de Corzo y los olmecas”, Arqueología Mexicana, 107: 74-83. México: Raíces.

2012 "Chiapa de Corzo's Mound 11 Tomb and the Middle Formative Olmec", Arqueología Reciente de Chiapas: Contribuciones del Encuentro Celebrado en el $60^{\circ}$ Aniversario de la Fundación Arqueológica Nuevo Mundo, pp. 45-68, Lynneth S. Lowe y Mary E. Pye (eds.). Provo: Brigham Young University (Papers of the New World Archaeological Foundation, 72).

s.f. "Centering Community: Olmec Geomancy at Chiapa de Corzo Mound 11", ponencia presentada en el foro "The Development of a Formal Middle Formative Site Layout in Southern Mesoamerica" en la 78th Annual Meeting of the Society for American Archaeology, Honolulu, Hawaii.

Bachand, Bruce R., Emiliano Gallaga Murrieta y Lynneth S. Lowe

2008 "The Chiapa de Corzo Archaeological Project: Report of the 2008 Field Season”, informe entregado al Instituto Nacional de Antropología e Historia, 236 pp. (http://chiapadecorzo.byu.edu).

Borhegyi, Stephen F. de

1951 "Further Notes on Three-Pronged Incense Burners and Rim-Head Vessels in Guatemala", Carnegie Institution of Washington, Notes on Middle American Archaeology and Ethnology, 4 (105): 162-176. Cambridge, Massachusetts.

Bryant, Douglas D.

2004 "Un yacimiento de ámbar recientemente descubierto cerca de Totolapa", Ámbar de Chiapas: Historia, ciencia y estética, pp. 96-99, Thomas A. Lee (coord.). Tuxtla Gutiérrez: Gobierno del Estado de Chiapas / Secretaría de Economía.

Cheetham, David

2010 "America's First Colony: Olmec Materiality and Ethnicity at Canton Corralito, Chiapas, Mexico", tesis de doctorado en Antropología. Tempe: Arizona State University.

Cheetham, David y Thomas A. Lee

2005 "Cerámica zoque temprana en Chiapa de Corzo: Secuencia, transición y relaciones externas”, Anuario 2004, pp. 287-315. Tuxtla Gutiérrez: Universidad de Ciencias y Artes de Chiapas.

Clark, John E.

1988 The Lithic Artifacts of La Libertad, Chiapas, Mexico: An Economic Perspective. 
Provo: Brigham Young University (Papers of the New World Archaeological Foundation, 52).

1993 “¿Quiénes fueron los olmecas?”, Segundo y Tercer Foro de Arqueologia de Chiapas, pp. 45-55, M. de M. Pedrero Corzo de Setzer (coord.). Tuxtla Gutiérrez: Gobierno del Estado de Chiapas / Instituto Chiapaneco de Cultura.

2000 "Los pueblos de Chiapas en el Formativo", Las culturas de Chiapas en el periodo prehispánico, pp. 37-85, D. Ségota (ed.). Tuxtla Gutiérrez: Conaculta.

Clark, John E., Barbara Arroyo y David Cheetham

2005 "Early Preclassic and Early Middle Preclassic Ceramics", Ceramic Sequence of the Upper Grijalva Region, Chiapas, Mexico, Part 1, pp. 21-139, D. D. Bryant, J. E. Clark y D. Cheetham (eds.) Provo: Brigham Young University (Papers of the New World Archaeological Foundation, 67).

Clark, John E. y David Cheetham

2005 "Cerámica del Formativo de Chiapas", La producción alfarera en el México antiguo I, pp. 285-433, B. L. M. Carrión y Á. G. Cook (eds.). México: Instituto Nacional de Antropología e Historia (Colección Científica, Serie Arqueología).

Clark, John E. y Richard D. Hansen

2001 "The Architecture of Early Kingship: Comparative Perspective on the Origin of the Maya Royal Court", Royal Courts of the Ancient Maya, Volume Two: Data and Case Studies, pp. 1-45, T. Inomata y S. D. Houston (eds.). Boulder: Westview Press.

Clark, John E. y John G. Hodgson

2007-2008 "Olmec Sculpture from Coastal Chiapas, Mexico", Thule: Revista Italiana di Studi Americanistici, 22/23-24/25: 41-99. Perugia: Centro Studi Americanistici.

Coe, Michael D. y Richard A. Diehl

1980 In the Land of the Olmec: The Archaeology of San Lorenzo Tenochtitlán. Austin: University of Texas Press, 2 vols.

Demarest, Arthur A.

1976 "A Re-evaluation of the Archaeological Sequences of Preclassic Chiapas", Studies in Middle American Anthropology, pp. 75-107. New Orleans: Tulane University (Middle American Research Institute, Publication 22).

Dixon, Keith A.

1959 Ceramics from Two Preclassic Periods at Chiapa de Corzo, Chiapas, Mexico. Provo: Brigham Young University (Papers of the New World Archaeological Foundation, 4).

Drucker, Philip

1952 La Venta, Tabasco: A Study of Olmec Ceramics and Art. Washington, D.C.: Smithsonian Institution. 
Drucker, Philip, Robert F. Heizer y Robert J. Squier

1959 Excavations at La Venta,Tabasco, 1955. Washington, D.C.: Smithsonian Institution.

García Cook, Ángel y Beatriz Leonor Merino Carrión

2005 "La Cerámica del Formativo en Puebla-Tlaxcala", La producción alfarera en el México antiguo I, pp. 575-649, B. L. M. Carrión y Á. G. Cook (eds.). México: Instituto Nacional de Antropología e Historia (Colección Científica, Serie Arqueología).

González, Dora de y Ronald K. Wetherington

1978 "Incensarios and Other Ceremonial Forms at Kaminaljuyu", The Ceramics of Kaminaljuyu, Guatemala, pp. 279-298, R. K. Wetherington (ed.). College Park: Pennsylvania State University (Monograph Series on Kaminaljuyu).

Grove, David C.

1989 "Chalcatzingo and Its Olmec Connection", Regional Perspectives on the Olmec, pp. 122-147, R. J. Sharer y D. C. Grove (eds.). Cambridge: Cambridge University Press (School of American Research Advanced Seminar Series).

Gussinyer, Jordi

1972 "Rescate arqueológico en la presa de La Angostura (primera temporada)", Boletín INAH Epoca II, abril-junio: 3-14.

Hermes, Bernard y Juan Luis Velásquez

1996 "El complejo cerámico Majadas de Kaminaljuyú”, IX Simposio de Investigaciones Arqueológicas en Guatemala, 1995, pp. 439-450, J. P. Laporte y H. L. Escobedo (eds.). Guatemala: Ministerio de Cultura y Deportes, Instituto de Antropología e Historia y la Asociación Tikal.

Hicks, Frederick y Charles E. Rozaire

1960 Mound 13, Chiapa de Corzo, Chiapas, Mexico. Provo: Brigham Young University (Papers of the New World Archaeological Foundation, 10).

Joralemon, Peter David

1971 A Study of Olmec Iconography. Washington D.C.: Dumbarton Oaks.

Lee, Thomas A.

1969 "Salvamento arqueológico en Chiapa de Corzo", Boletín del Instituto Nacional de Antropología e Historia, 38: 17-22. México: Instituto Nacional de Antropología e Historia.

1974 Mound 4 Excavations at San Isidro, Chiapas, Mexico. Provo: Brigham Young University (Papers of the New World Archaeological Foundation, 34).

1993 "Evidencia olmeca en el dominio de Chiapa de Corzo", Segundo y Tercer Foro de Arqueologia de Chiapas, pp. 228-235, M. de M. Pedrero Corzo de Setzer (coord.). Tuxtla Gutiérrez: Gobierno del Estado de Chiapas / Instituto Chiapaneco de Cultura. 

estética, pp. 100-116, Thomas A. Lee (coord.). Tuxtla Gutiérrez: Gobierno del Estado de Chiapas / Secretaria de Economía.

León, Francisco de y Juan Antonio Valdés

2002 "Excavaciones en Piedra Parada: Más información sobre el Preclásico Medio del Altiplano Central de Guatemala", Incidents of Archaeology in Central America and Yucatán: Essays in Honor of Edwin M. Shook, pp. 375-395, M. Love, M. Popenoe de Hatch y H. L. Escobedo (eds.). New York / Oxford: University Press of America, Inc.

Lowe, Gareth W.

1962 Mound 5 and Minor Excavations, Chiapa de Corzo, Chiapas, Mexico. Provo: Brigham Young University (Papers of the New World Archaeological Foundation, 12).

1977 "The Mixe-Zoque as Competing Neighbors of the Early Lowland Maya”, The Origins of Maya Civilization, pp. 197-248, R. E. W. Adams (ed.). Albuquerque: University of New Mexico Press (School of American Research Advanced Seminar Series).

1978 "Eastern Mesoamerica”, Chronologies in New World Archaeology, pp. 331-393, R. E. Taylor y C. W. Meighan (eds.). New York: Academic Press.

1981 "Olmec Horizons Defined in Mound 20, San Isidro, Chiapas", The Olmec and Their Neighbors: Essays in Memory of Matthew W. Stirling, pp. 231-255, Elizabeth P. Benson (ed.), Michael D. Coe y David Grove (coords.). Washington, D.C.: Dumbarton Oaks.

1991 "Buscando una cultura olmeca en Chiapas", Primer foro de Arqueología de Chiapas: Cazadores-recolectores-pescadores y agricultores tempranos, pp. 111130. Tuxtla Gutiérrez: Gobierno del Estado de Chiapas.

1998 Los olmecas de San Isidro en Malpaso, Chiapas. México: Instituto Nacional de Antropología e Historia / Universidad Nacional Autónoma de México, Centro de Investigaciones Humanísticas de Mesoamérica / Estado de Chiapas.

1999 Los zoques antiguos de San Isidro. Tuxtla Gutiérrez: Consejo Estatal para la Cultura y las Artes de Chiapas.

2007 "Early Formative Chiapas: The Beginnings of Civilization in the Central Depression of Chiapas", Archaeology, Art, and Ethnogenesis in Mesoamerican Prehistory: Papers in Honor of Gareth W. Lowe, pp. 63-108, L. S. Lowe y M. E. Pye (eds.). Provo: Brigham Young University (Papers of the New World Archaeological Foundation, 68).

s.f. "Southern Olmecs and Preclassic Zoques in Western Chiapas: Summary of Research and Writing, 1993”, manuscrito no publicado. Provo: Brigham Young University, Department of Anthropology.

Lowe, Gareth W. y Pierre Agrinier

1960 Mound 1, Chiapa de Corzo, Chiapas, Mexico. Provo: Brigham Young University. (Papers of the New World Archaeological Foundation, 8).

Lowe, Gareth W. y J. Alden Mason

1965 "Archaeological Survey of the Chiapas Coast, Highlands, and Upper Grijalva 
Basin”, Handbook of Middle American Indians, Vol. 2: Archaeology of Southern Mesoamerica, pp. 195-236, G. R. Willey (ed.). Austin: University of Texas Press.

Lowe, Gareth W., Thomas A. Lee Jr. y Eduardo Martínez Espinosa

1982 Izapa: An Introduction to the Ruins and Monuments. Provo: Brigham Young University (Papers of the New World Archaeological Foundation, 8).

Lowe, Lynneth S.

2005 El ámbar de Chiapas y su distribución en Mesoamérica. México: Universidad Nacional Autónoma de México, Instituto de Investigaciones Filológicas, Centro de Estudios Mayas (Cuadernos del Centro de Estudios Mayas, 30).

2009 "Exoloración de un basurero del periodo Preclásico Medio en Chiapa de Corzo, Chiapas", ponencia presentada en la 74th Annual Meeting of the Society for American Archaeology, Atlanta, Georgia.

Mason, J. Alden

1960 Mound 12, Chiapa de Corzo, Chiapas, Mexico. Provo: Brigham Young University (Papers of the New World Archaeological Foundation, 9).

Miller, Donald E., Douglas D. Bryant, John E. Clark y Gareth W. Lowe

2005 "Middle Preclassic Ceramics", Ceramic Sequence of the Upper Grijalva Region, Chiapas, Mexico, Part 1, pp. 141-264, D. D. Bryant, J. E. Clark y D. Cheetham (eds.). Provo: Brigham Young University (Papers of the New World Archaeological Foundation, 67).

Navarrete, Carlos

1959 Explorations at San Agustin, Chiapas, Mexico. Orinda, CA: Brigham Young University (Papers of the New World Archaeological Foundation, 3).

Pinkowski, Jennifer

2006 "A City by the Sea: Early Urban Planning on Mexico's Pacific Coast", Archaeology, 59 (1): 46-49. New York: Archaeological Institute of America.

Pohl, Mary

2005 "Olmec Civilization at San Andres, Tabasco, Mexico", informe entregado a la Foundation for the Advancement of Mesoamerican Studies, Inc. (FAMSI), 50 pp. (www.famsi.org/reports/01047/index.html).

Popenoe de Hatch, Marion

2007 "The Mesoamerican Preclassic: A View from the South Coast of Guatemala", Archaeology, Art, and Ethnogenesis in Mesoamerican Prehistory: Papers in Honor of Gareth W. Lowe, pp. 161-171, L. S. Lowe y M. E. Pye (eds.). Provo: Brigham Young University (Papers of the New World Archaeological Foundation, 68).

Reyes, Liliana Carla y Marcus Winter

2010 "The Early Formative Period in the Southern Isthmus: Excavations at Barrio Tepalcate, Ixtepec, Oaxaca”, Ancient Mesoamerica, 21: 151-163. Nashville: Cambridge University Press. 
Sabloff, Jeremy A.

1975 Excavations at Seibal, Department of Peten, Guatemala: Ceramics. Gordon R. Wiley (ed.). Cambridge: Harvard University (Memoirs of the Peabody Museum of Archaeology and Ethnology, 13-2).

Sisson, Edward B.

1976 "Survey and Excavation in the Northwestern Chontalpa, Tabasco, Mexico", tesis de doctorado. Cambridge, MA: Harvard University.

Stark, Barbara L.

1999 "Commentary: Ritual, Social Identity, and Cosmology: Hard Stones and Flowing Water", Social Patterns in Pre-Classic Mesoamerica, pp. 301-318, D. C. Grove y R. A. Joyce (eds.). Washington, D.C.: Dumbarton Oaks.

Sullivan, Timothy D.

2009 "The Social and Political Evolution of Chiapa de Corzo, Chiapas, Mexico: An Analysis of Changing Strategies of Rulership in a Middle Formative Through Early Classic Mesoamerican Political Center", tesis de doctorado en Antropología. Pittsburgh: University of Pittsburgh.

Taube, Karl

1996 "The Olmec Maize God: The Face of Corn in Formative Mesoamerica", Res: Anthropology and Aesthetics, 29/30: 39-81. Cambridge, MA: Peabody Museum of Archaeolgy and Ethnology, Harvard University.

Vásquez Campa, Violeta y Marcus Winter

2009 "Mixes, zoques y la arqueología del Istmo Sur de Tehuantepec", Medio ambiente, antropología, historia y poder regional en el occidente de Chiapas y el Istmo de Tehuantepec, pp. 219-234, Thomas A. Lee Whiting, Davide Domenici, Victor M. Esponda J., Carlos U. del Carpio Penagos (coords.). Tuxtla Gutiérrez, Chiapas: Universidad de Ciencias y Artes de Chiapas.

Velásquez, Juan Luis

1991 "Replanamiento de la fase Majadas: Un componente preclásico medio tardío", II Simposio de Investigaciones Arqueológicas en Guatemala, 1988, pp. 7380, M. O. Corzo (ed.). Guatemala: Ministerio de Cultura y Deportes / Asociación Tikal.

Von Nagy, Christopher L.

2003 "Of Meandering Rivers and Shifting Towns: Landscape Evolution and Community Within the Grijalva Delta", tesis de doctorado en Antropología. New Orleans: Tulane University.

Warren, Bruce W.

1961 "The Archaeological Sequence at Chiapa de Corzo", VIII Mesa Redonda de la Sociedad Mexicana de Antropología: Los mayas del sur y sus relaciones con los nahuas meridionales, pp. 75-83. San Cristobal de las Casas: Sociedad Mexicana de Antropología. 
1978 "The Sociocultural Development of the Central Depression of Chiapas, Mexico: Preliminary Considerations", tesis de doctorado en Antropología. Tucson: University of Arizona.

Wichmann, Søren, Dmitri Beliaev y Albert Davletshin

2008 "Possibles correlaciones linguiísticas y arqueológicas vinculadas con los olmecas", Olmeca: Balance y perspectivas, pp. 667-683, M. T. Uriarte y R. B.González Lauck (eds.). México: Universidad Nacional Autónoma de México, Instituto de Investigaciones Estéticas.

Willey, Gordon R., Gordon F. Ekholm y René F. Millon

1964 "The Patterns of Farming Life and Civilization", Handbook of Middle American Indians, Vol. 1: Natural Environment and Early Cultures, pp. 446-498, R. C. West (ed.). Austin: University of Texas Press.

Zeitlin, Robert

1979 "Prehistoric Long-Distance Exchange on the Southern Isthmus of Tehuantepec", tesis de doctorado en Antropología. Ann Arbor: University of Michigan. 